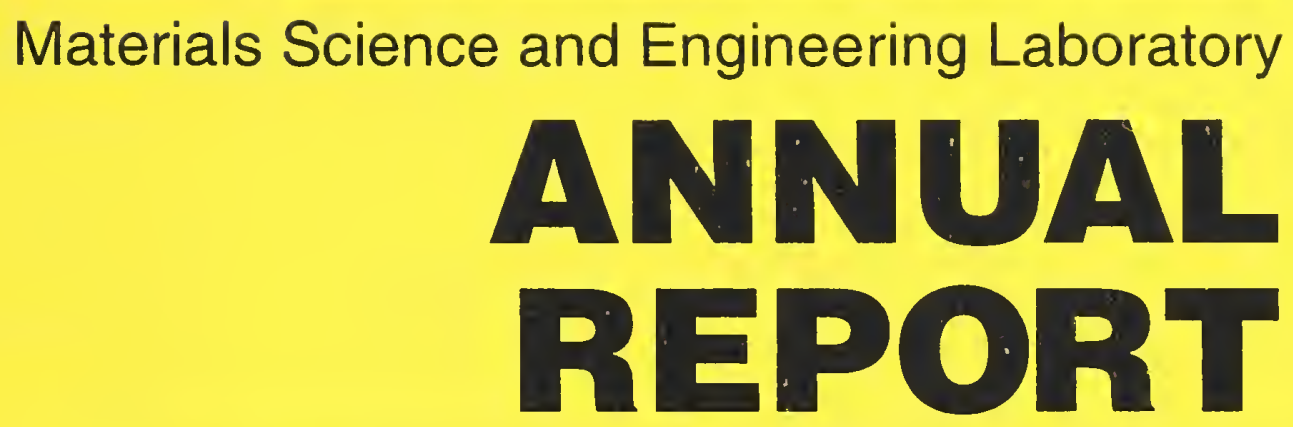

1995

QC

100

.056

N0.5746

1995

NISTIR 5746

U.S. Department of Commerce Technology Administration National Institute of Standards and Technology
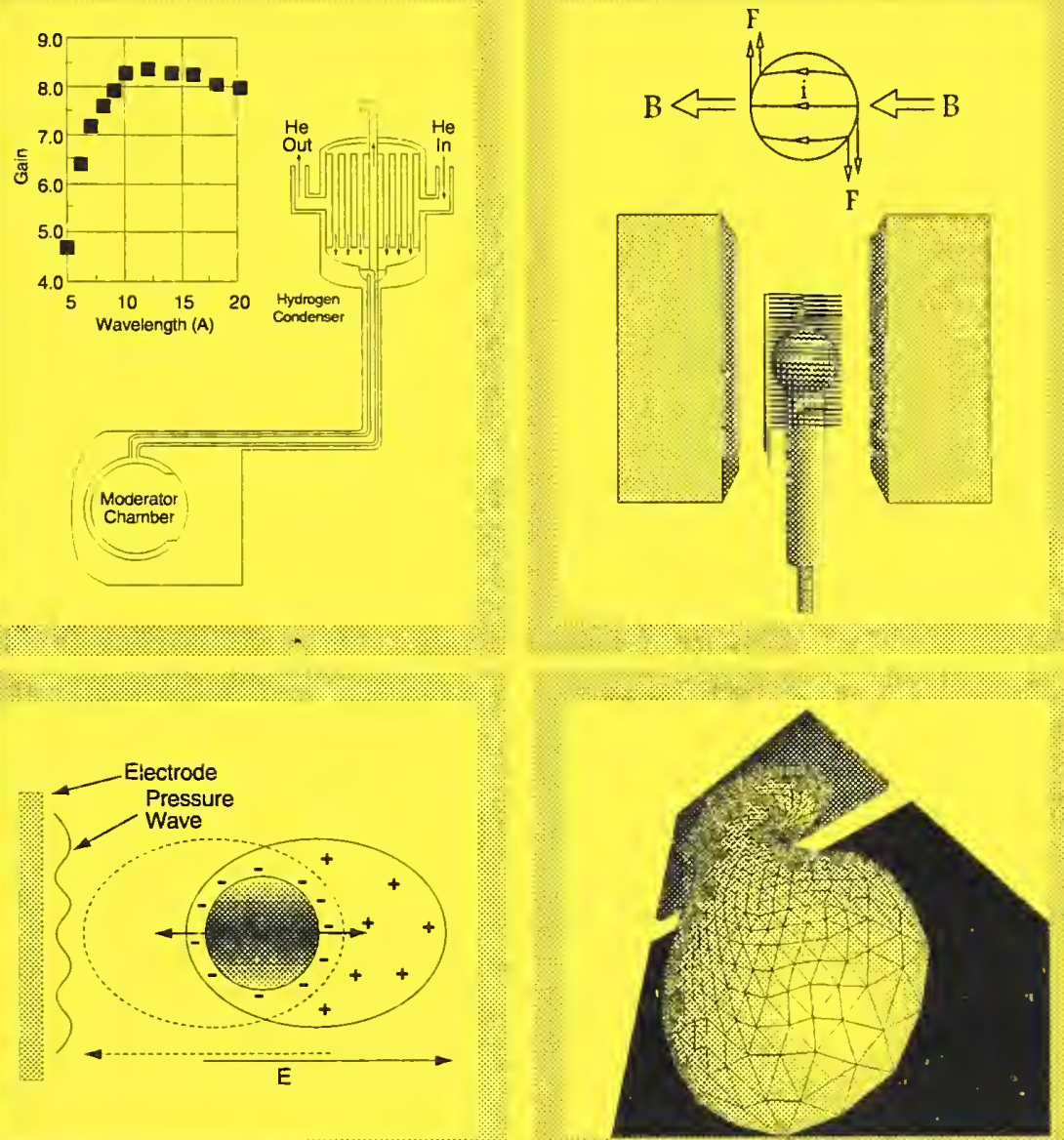
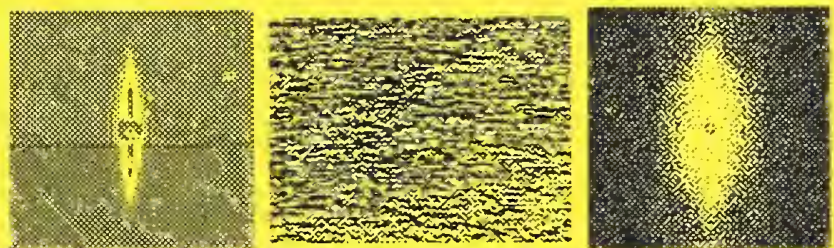


\section{MATERIALS SCIENCE AND ENGINEERING LABORATORY}

\section{L.H. Schwartz, Director \\ H.L. Rook, Deputy Director}

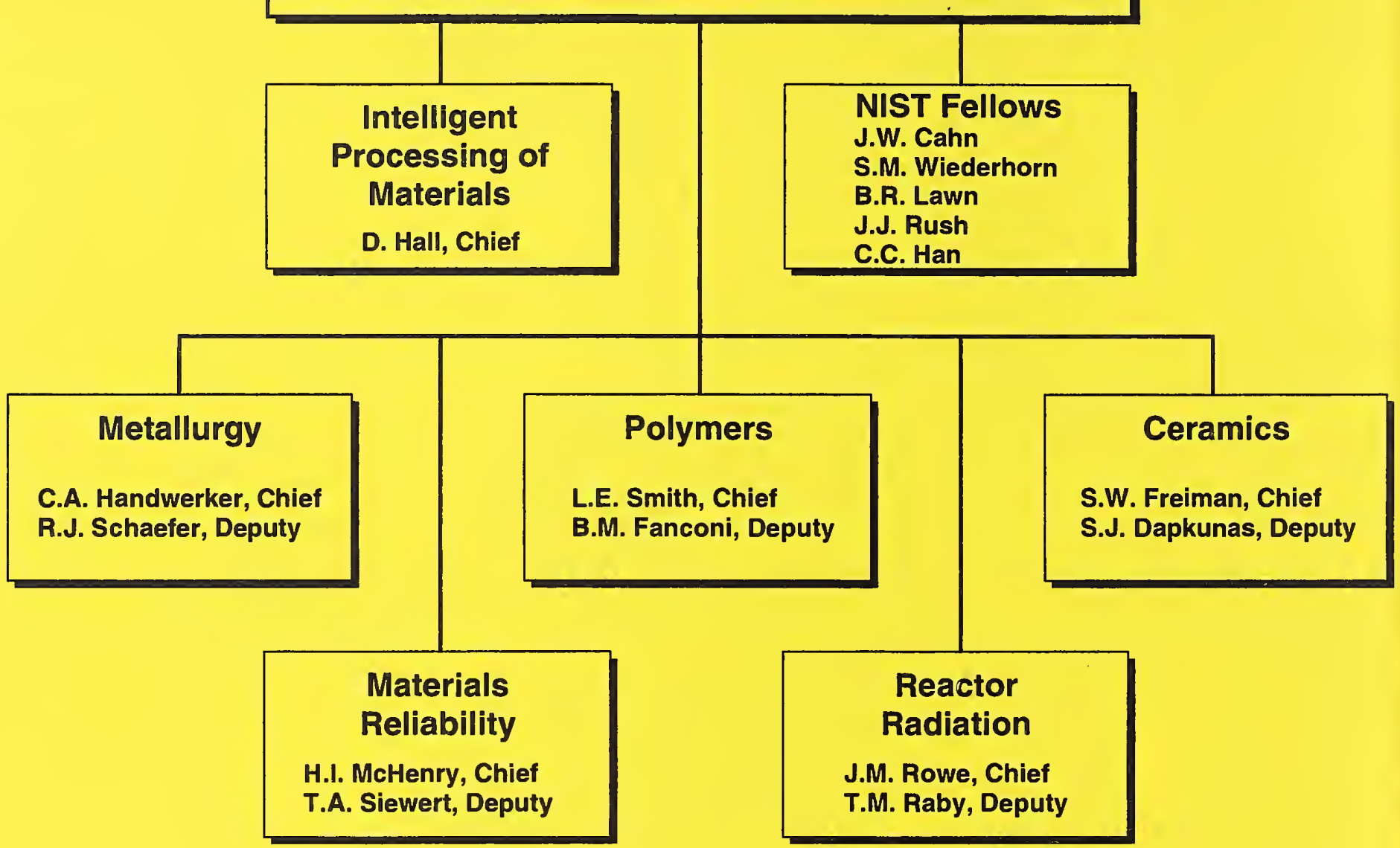

Annual report covers for the five operating divisions (Ceramics, Metallurgy, Polymers, Reactor Radiation, and Materials Reliability) of the Materials Science and Engineering Laboratory. These annual reports describe in detail the technical activities of each of the Laboratory's major units and are available on request. 


\section{Materials Science and Engineering Laboratory}

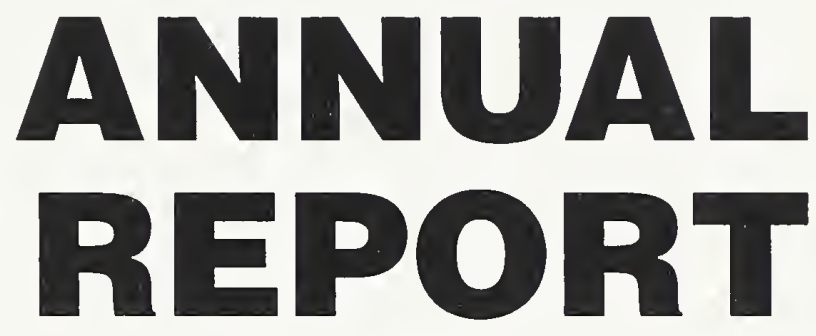

L.H. Schwartz, Director

H.L. Rook, Deputy

NISTIR 5746

U.S. Department of Commerce

Technology Administration

National Institute of Standards

and Technology

\section{Technical Activities 1995}

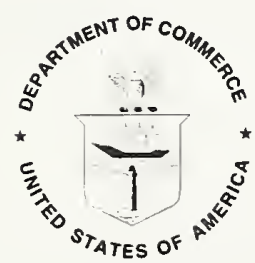

U.S. DEPARTMENT OF COMMERCE

Ronald H. Brown, Secretary

TECHNOLOGY ADMINISTRATION

Mary L. Good, Under Secretary for Technology

NATIONAL INSTITUTE OF STANDARDS

AND TECHNOLOGY

Arati Prabhakar, Director 


\section{TABLE OF CONTENTS}

Page

PREFACE .

OFFICE OF THE DIRECTOR

iii

OVERVIEW .

1

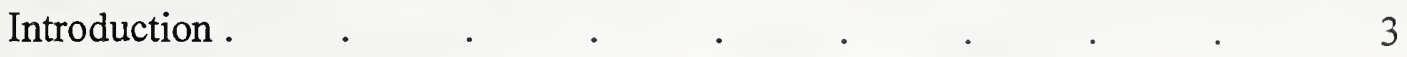

Organization of Technical Staff. . $\quad$. $\quad$. $\quad . \quad$. $\quad$. 3

Organization of Technical Activities . . . . . . . . 5

Selected Accomplishments and Impacts . . $\quad$. $\quad$. $\quad$. $\quad$. 7

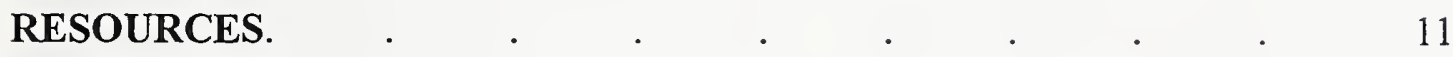

MSEL 1995 Budget Profile . $\quad$. $\quad$. $\quad$. $\quad$. $\quad$. 13

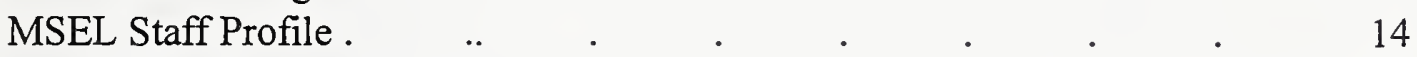

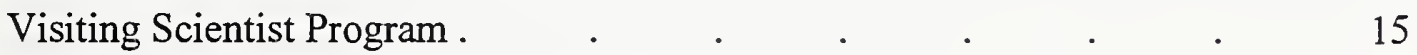

NRC-NAE-NAS Post Doctoral Program . . . . . . . . . $\quad 16$

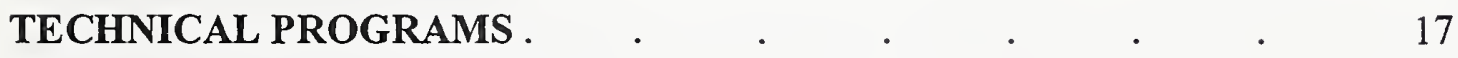

TECHNOLOGY TRANSFER. . . . . . . . . . 41

Summary of CRADA Activities . . $\quad$. $\quad$. $\quad$. $\quad$. 43

Active CRADAs FY 1995 . $\quad$. $\quad$. . . . . . 45

Patents Granted . . $\quad$. $\quad$. $\quad$. . . . . 55

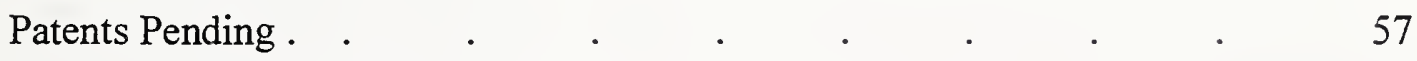

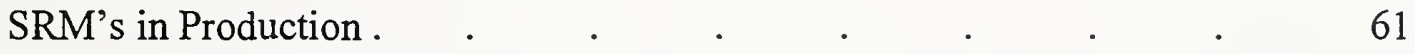

SRM Projects Under Development .. $\quad . \quad \ldots \quad$ • $\quad . \quad$. $\quad . \quad 62$

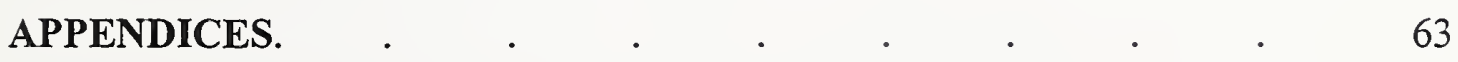

Honors and Awards . $\quad . \quad$. $\quad . \quad$. . . $\quad$. 65

Collage of Covers for Division Reports . . . . . . . . . . . C Cover 1

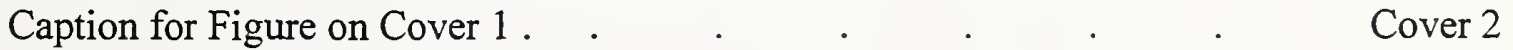

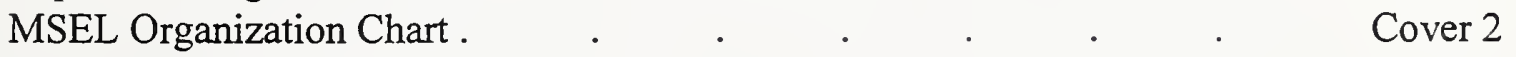

NIST Organization Chart . . $\quad . \quad \ldots \quad$. $\quad . \quad$. $\quad . \quad$. $\quad$ Cover 3 



\section{PREFACE}

The National Academy of Sciences-National Academy of Engineering-National Research Council (NAS-NAE-NRC) Board on Assessment of the National Institute of Standards and Technology (NIST) Programs, and in particular, the Panel for Materials Science and Engineering performs an important role in support of the programs and success of the Materials Science and Engineering Laboratory (MSEL). The Panel is one of our most effective means of technical peer review by counterparts in the scientific and engineering communities of U.S. industry and academe. Each panel member is selected by the National Research Council on the basis of expertise and extensive experience in the areas of research and technology conducted by the Laboratory.

The 1995 Annual Report was organized to assist the NAS-NAE-NRC Board on Assessment and intended to be used as background information at the annual review meeting. Coupled with the more detailed technical reports of the divisions of MSEL, this report describes the activities, accomplishments, output and impacts of the MSEL during the period of Fiscal Year 1995 (October 1, 1994 to September 30, 1995). Although, the normal evaluation process was aborted this year by the prolonged closing of NIST, the report has been completed to maintain continuity of information flow and assist the panel in its 1996 review.

In addition to the NAS-NAE-NRC Panel this report is also made available to those in industry, academic institutions and government agencies who wish to know more about our technical activities and it to this audience that we are primarily directing our 1995 Annual Report. I appreciate hearing the Panel's comments about the information contained herein. This information may also be used by our customers to identify ways in which we may more effectively serve your needs. I and my staff look forward to working with you in the future.

Lyle H. Schwartz 


\section{•}




\section{OFFICE OF THE DIRECTOR}

\section{MATERIALS SCIENCE AND ENGINEERING LABORATORY}

\section{DIRECTOR}

Lyle H. Schwartz

(301) 975-5658

E-Mail: lyle.schwartz@nist.gov

DEPUTY DIRECTOR

Harry L. Rook

(301) 975-5658

E-Mail: harry.rook@nist.gov

\section{SCIENTIFIC ADVISORS}

Daniel B. Butrymowicz*

James G. Early

(301) 975-6113

E-Mail: james.early@nist.gov

Kenneth L. Jewett

(301) 975-2608

E-Mail: kenneth.jewett@nist.gov

Samuel J. Schneider

(301) 975-5657

E-Mail: samuel.schneider@nist.gov

\section{SENIOR MANAGEMENT ADVISOR}

Paul Fleming

(301) 975-5653

E-Mail: paul.fleming@nist.gov
ADMINISTRATIVE OFFICER

Patricia Salpino

(301) 975-5731

E-Mail: patty.salpino@nist.gov

NIST SENIOR FELLOWS

John Cahn

(301) 975-5664

E-Mail:john.cahn@nist.gov

Sheldon Wiederhorn

(301) 975-5772

E-Mail: sheldon.wiederhorn@nist.gov

\section{NIST FELLOWS}

Charles Han

(301) 975-6772

E-Mail: charles.han@nist.gov

Brian Lawn

(301) 975-5775

E-Mail: brian.lawn@nist.gov

Jack Rush

(301) 975-6220

E-Mail: john.rush@nist.gov

Robb Thomson (Emeritus)

(301) 975-5665

E-Mail: robb.thomson@nist.gov

*Deceased 
OVERVIEW 
OVERVIEW 



\section{INTRODUCTION}

The Materials Science and Engineering Laboratory provides technical leadership and participates in developing the measurement and standards infrastructure related to materials critical to U.S. industry, academia, government and the public. MSEL's mission is to stimulate the more effective production and use of materials by working with materials suppliers and users to assure the development and implementation of the measurements and standards infrastructure for materials. Materials science and engineering programs at NIST cover a full range of materials issues from design to processing to performance.

Separate research initiatives address ceramics, metals, polymers, composites, and superconductors. This research supports efforts of U.S. industry to develop reliable, low cost manufacturing methods for producing tailor-made materials and products with superior properties.

Through laboratory-organized consortia and one-to-one collaborations, NIST's materials scientists and engineers work closely with industrial researchers. Examples include work on improved processing of rapidly solidified metal powders, polymer composites, ceramic machining, casting of aerospace alloys, and materials property sensors for aluminum and steel manufacturing. The laboratory is also strengthening its relationships with manufacturers of hightechnology products, the major users of advanced materials.

Our dedicated technical and support staff seeks to leverage the resources under our control to effect the greatest impact of our activities chosen to accomplish this mission. Planning, therefore, is an important element of that selection process. Thus, we treat MSEL's Strategic Plan as a living document which must be (and is) periodically revised to keep pace with the changing needs of materials suppliers and users.

This report summarizes MSEL's technical activities for FY 1995. More specific information about these activities may be obtained by reviewing the annual reports from our five technical divisions.

\section{ORGANIZATION OF TECHNICAL STAFF}

The Materials Science and Engineering Laboratory is one of the eight technical laboratory-based operating units of the National Institute of Standards and Technology (NIST). The FY 1994 MSEL budget was approximately $\$ 62.7$ million, including capital equipment acquisitions. MSEL has a total staff of 387, of which 79 percent are in full time scientific or technical support positions. In addition, MSEL had 525 visiting scientists and engineers during Fiscal Year 1994 involved in collaborative research and over 1025 research participants and users of the NIST research reactor and Cold Neutron Research Facility. These non-NIST researchers provide significant leverage of MSEL staff and resources. 
The Laboratory consists of five technical divisions, including the three material specific divisions of Ceramics, Metallurgy, and Polymers, the interdisciplinary Materials Reliability Division, and the Reactor Radiation Division; and one independent program office, Intelligent Processing of Materials (see Appendix D). Each of the six units has the generic mission of fostering the economical processing and safe and efficient use of materials and materials products by improving materials quality, manufacturability, and reliability. This mission is accomplished through developing and disseminating standards, measurement methods, predictive models, evaluated data and reference materials, and the scientific, quantitative understanding that is fundamental to the synthesis, processing, characterization, properties, and performance of materials.

\section{Office of Intelligent Processing of Materials (OIPM)}

OIPM has the responsibility of fostering concepts, and building and overseeing programs in the intelligent processing of materials (IPM). The Office also administers the MSEL Center for Theoretical and Computational Materials Science (CTCMS). IPM programs encompass the application and development of on-line, real-time process sensors; models that connect the process variables with the desired microstructure and macroscopic material properties; and computer control systems that incorporate the process models and sensor data and provide process control via a feedback loop. The CTCMS is a distributed center with members at NIST and elsewhere. Its primary purpose is to develop and apply state-of-the-art materials theory and computational techniques and to help industry integrate them into technology development.

\section{Ceramics Division}

The Ceramics Division conducts programs pertinent to advanced ceramic materials through fundamental and applied research, the development of standard test methodologies, the preparation of standard reference materials, and the evaluation and dissemination of standard reference data. The Division addresses key scientific issues concerned with the relations between processing and structure at the atomic, molecular, and microscale levels and the ways in which those structures affect properties and performance.

\section{Materials Reliability Division}

The Materials Reliability Division fosters the increased use of advanced materials in commercial products by research aimed at improving confidence in their service performance. Measurement technology is developed for process control to improve quality, consistency and manufacturability of materials, nondestructive evaluation to assure quality of finished materials and products, fitness-for-purpose standards to relate material quality to reliability and safety, and materials evaluation to assure reliable performance. 


\section{Polymers Division}

The Polymers Division provides standards, measurement methods, and fundamental concepts of polymer science to assist U.S. industries that produce or use polymers as essential parts of their business. This broad mission has been focussed to match the finite resources and technical capabilities of the Division. Industrial input into program planning and direction come from NIST/Industry Workshops on topics important to the competitiveness of U.S. industries.

\section{Metallurgy Division}

Materials processing is now firmly established as the central thrust of the Division's programs, with a clear focus on process control. The Division's processing programs are grouped into four main areas, namely liquid-solid metal processing, electroforming, thin-film vapor deposition, and processing of steel sheet. This strategy has allowed the Division to respond effectively to NIST's expanded mandate, fostering closer and more focused interaction with U.S. industry, and to retain its traditional strengths in measurement science.

\section{Reactor Radiation Division}

The Reactor Radiation Division has three primary responsibilities: to operate the research reactor (NBSR) as a NIST and national resource in a cost-effective manner while assuring the public safety; to conduct a broad program of materials research using neutron methods, while developing and maintaining state-of-the-art instrumentation to ensure the best utilization of the NBSR neutron scattering facilities; and to develop and operate the Cold Neutron Research Facility (CNRF) as a national center, providing unique measurement capabilities to U.S. researchers.

\section{ORGANIZATION OF TECHNICAL ACTIVITIES}

The Laboratory's technical activities are described in terms of research projects, research programs or strategic thrusts. Research projects are research and development activities having defined technical objectives, work plan, and planned outputs that address a specific technical opportunity or barrier in materials science.

Research programs are assemblies of research projects designed to collectively accomplish technical goals and objectives to overcome technical barriers in a specific technological area. Research programs are organized and managed as a collective set of projects and may reside within a single group, one division within MSEL or may extend to other laboratories within NIST.

Strategic thrusts are selected assemblies of research projects organized to collectively accomplish technical objectives in specific goal areas of MSEL/NIST. The MSEL strategic thrusts for FYs 
1995-1997 and beyond are: Advanced Materials; Measurements and Standards (for materials); Advanced Processing; and National User Facilities. Note that some programs may fit under more than one strategic thrust; a list of FY 1995 strategic thrusts and the identity of programs that represent their majority focus for that effort follows.

ADVANCED MATERIALS

Dental and Medical Materials

Electronic and Photonic Materials

Mechanical Properties of Brittle Materials

Theory and Modeling

ADVANCED PROCESSING

Ceramic Coatings

Ceramic Machining

Ceramic Processing

Intelligent Processing of Materials

Metals Processing

Polymer Blends

Polymer Composites

MEASUREMENTS AND STANDARDS

Biotechnology

Electronic Packaging and Interconnection

Evaluated Materials Data

High Temperature Superconductivity

Metals Data and Characterization

Nanostructured Materials

Neutron Characterization

Nondestructive Evaluation

Polymer Characterization

Standard Reference Materials

Synchrotron Radiation

Viscoelasticity of Polymers

NATIONAL USER FACILITY

NIST Research Reactor 


\section{SELECTED ACCOMPLISHMENTS AND IMPACTS}

The Materials Science and Engineering Laboratory conducts its programs in a manner that ensures the greatest impact for our $\mathrm{R} \& \mathrm{D}$ investments. The following listing represents a sampling of the Laboratory's successes in FY 1995. Accomplishments are listed either under one of the Laboratory's three strategic thrust titles or under National User Facility, which offer unique capability to investigate technical problems. A complete listing of accomplishments may be found in the annual reports for MSEL's divisions.

\section{ADVANCED MATERIALS}

- A cure sensor and process control system were developed in cooperation with industry and demonstrated in the fabrication of a polymer composite plaques. Northrop-Grumman has transferred the technology to their laboratory where it will be implemented on prototype production equipment as part of an ARPA program.

- A new class of magnetic thin films have been identified which exhibit the giant magnetoresistance effect (GMR), a large resistance change ( $>20 \%)$ in extremely small fields ( $<50$ times earth's field). The thin films, known as spin valves, consist of nanometer-scale multilayers of magnetic and non-magnetic materials and are rapidly finding applications as field sensors.

- A set of Standard Reference blocks for Knoop hardness have been fabricated and calibrated and are now available as Standard Reference Material \#2830. The blocks were prepared from silicon nitride bearing balls which were machined, polished, indented, and finally measured using a calibrated scanning electron microscope. Hardness is very uniform in each block and has been certified to within $1 \%$ at a $95 \%$ confidence level. These blocks will be used by the entire ceramic community including industry, academia and government. SRM 2830 is the first dedicated ceramic Knoop reference block in the world and will support the new ASTM Standard C 1326-96, Knoop Indentation Hardness of Advanced Ceramics.

\section{ADVANCED PROCESSING}

- A non-contacting, eddy-current thermometer for monitoring the temperature of sheet aluminum as it leaves the last stand of a rolling mill at high speed and high temperature was demonstrated at the Mill Products Division of Alumax Corporation in Lancaster, PA.

- Plant trials on the Arc Sensor Module (ASM) were conducted by an automotive components manufacturer. The ASM enabled real time detection of common welding problems which occurred in an eight robot welding cell, thereby demonstrating the ASM as a diagnostic tool for process control. 
- In collaboration with Dynisco a pressure/optical sensor which can be used to measure fluorescence and pressure simultaneously was developed.

- The NIST developed temperature measurement technologies based on fluorescence are being adopted by consortium members. $3 \mathrm{M}$ is using the technology in process modeling laboratories and Du Pont is working with NIST on the extensions to temperature profile measurements.

- A high refractive index fiber was used to demonstrate for the first time that a single fiber can be employed for cure monitoring with both fluorescence and near infra-red spectroscopies. The fluorescence work received a Best Paper award at the 1995 SPE/ANTEC Conference.

\section{MEASUREMENTS AND STANDARDS}

- In conjunction with the General Electric Company, the U.S. Air Force Rome Laboratory, and the University of Massachusetts, NIST provided quantitative data on the in situ local strains that surround buried interconnect vias in a polyimide - copper MCM-L high density interconnect structure using a micro-moiré interferometric technique. Intended to assist analytic approaches for predicting the performance of packages or interconnect structures, these NIST data were used by the team partners to compare and refine the strains predicted through modeling.

- Results from NIST solderability research on identification of test conditions that provide high sensitivity to wettability factors were incorporated by the Institute for Interconnecting and Packaging Electronic Circuits (IPC) Wetting Balance Task Group into the IPC Joint Industry Standard document on Solderability Tests for Component Leads, Terminations, Lugs, Terminals, and Wires.

- A new database, High Temperature Superconductors, SRD Database Number 62, was issued in a Windows environment. It is the first compilation of evaluated data on these materials and the first to be issued in a Windows format. The database contains physical, chemical, and electrical data of interest for a number of applications.

- A zirconia plasma spray powder Standard Reference Material for use in the calibration of light-scattering, powder-size-distribution-measurement instruments has been developed. The research leading to this development was carried out in collaboration with 11 companies active in the thermal spray field. This SRM will allow for the improved specification of thermal spray powders with associated improved deposition efficiencies, and process and property control.

- An improved microtensile testing system based on piezo devices, upgraded data acquisition equipment, and software has been developed to measure tensile and fatigue 
behavior of thin films. Fatigue tests with cycles of $10 \mathrm{~s}$ duration have been run out to over 100000 cycles. The apparatus has been used for tensile testing of a variety of thin films including epitaxial silicon (collaboration with Ford Microelectronics), electron beam evaporated copper, and aluminum.

Electromagnetic transducers were developed for measuring the stress in steel bridge girders by ultrasonic birefringence and Rayleigh wave techniques. They were used on bridges in West Virginia and Virginia to measure service induced loads that could not be measured by conventional strain gage techniques.

A NIST design for couplant free ultrasonic inspection of automotive air bag inflators was transferred to a test equipment manufacturer and three commercial units are now performing in-line inspections at production facilities of Morton International, Inc.

On December 3, 1994 the Reactor Radiation Division and NIH held a joint workshop on the potential applications of neutron spectroscopy to biomolecular dynamics. The dynamical behavior of biological macromolecules and associated water is often a key factor in determining biological function or biological processes. The workshop was attended by approximately 55 scientists from government laboratories, academia, and industry. Five invited speakers from the NIH and FDA described their research efforts, and elucidated specific questions which might be answered by performing complementary inelastic neutron scattering experiments.

\section{NATIONAL USER FACILITY}

A new soft-x-ray materials science end station for beam line U7A at the National Synchrotron Light Source has been designed, built and commissioned. This experimental station, which delivers state-of-the-art brightness and resolution, is the result of a collaboration between NIST, Dow Chemical Co., Brookhaven Physics Department, and two small business awardees of SBIRs.

The new hydrogen cold source at the CNRF--designed, fabricated, and tested by NIST scientists and engineers--was installed. Users of the CNRF will benefit enormously from the increase in cold neutron intensity that the new cold source provides. Over the 0.6 to $2.0 \mathrm{~nm}$ wavelength range, the intrinsic gain with respect to the original cold source is no less than 4.5. When the $15 \mathrm{MW}$ to $20 \mathrm{MW}$ increase in power is also included, the gain is between 6 and 8 over the same wavelength range (which is very close to design predictions). This and the other improvements at the NBSR secures, for years to come, NIST's position as the leading neutron research center in the country, directly competitive with the best in the world.

The NIST Reactor Radiation Division has recently joined with the University of Pennsylvania and the University of California at Santa Barbara, and their industrial 
partners--Dupont, Hughes Aircraft, and Allied Signal--to greatly advance U.S.

capabilities in neutron spectroscopy for studies of new materials. Joint efforts will be focused on the development and operation of a new high intensity neutron spectrometer which is expected to increase U.S. measurement capabilities in neutron vibrational spectroscopy by a factor of 100 , and is to be installed at the NIST reactor. In addition to leading the development of this instrument, NIST scientists will pursue joint generic and strategic research on new materials (e.g. catalysts, light-weight batteries, conducting polymers, fullerenes) with the university/industry research teams. One-quarter of the time on the new facility will be allocated to the general scientific community on the basis of scientific merit through the NIST proposal system. 
RESOURCES 


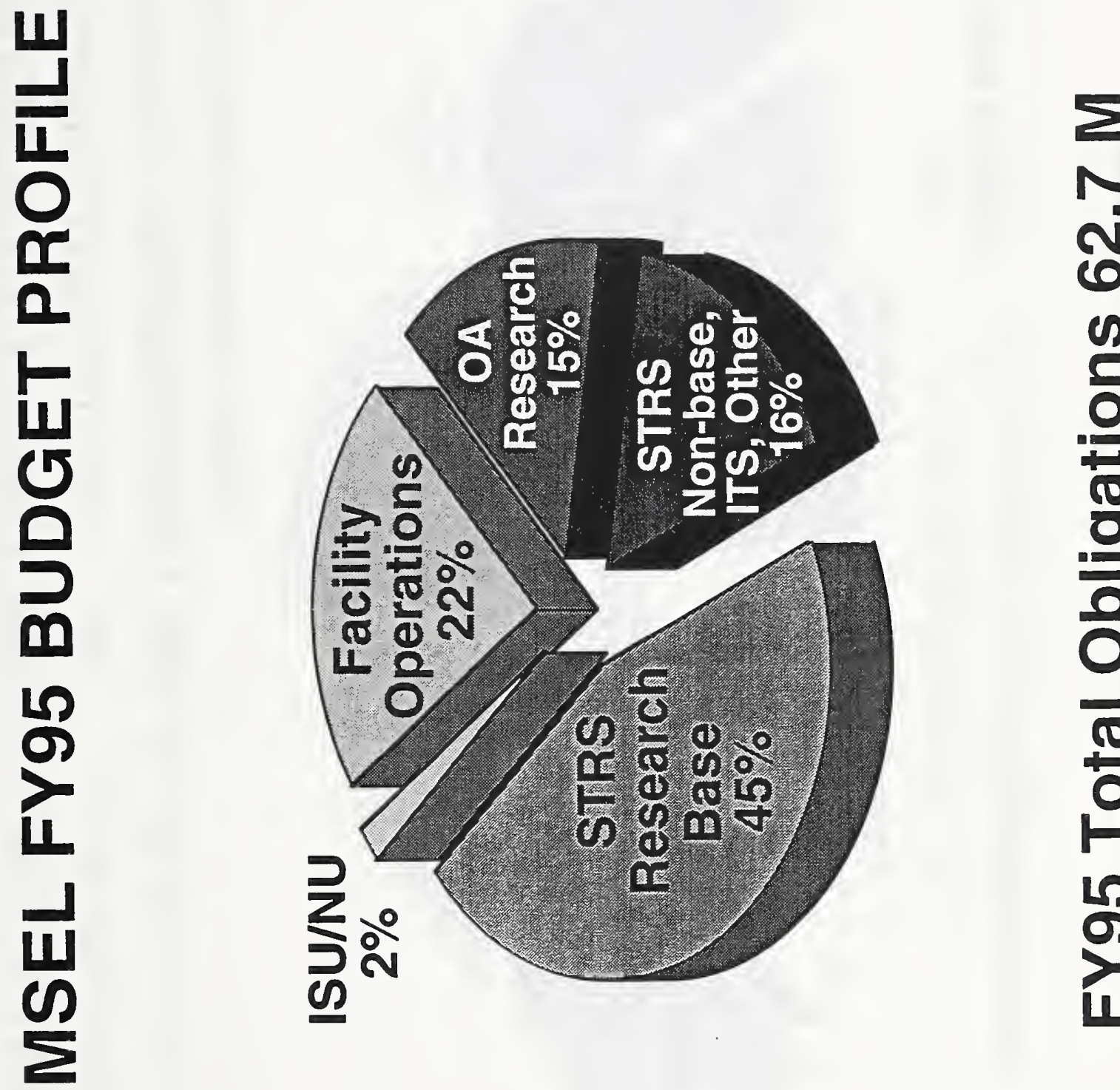

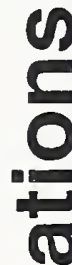

$\frac{0}{0}$

0
0
10
0
0 


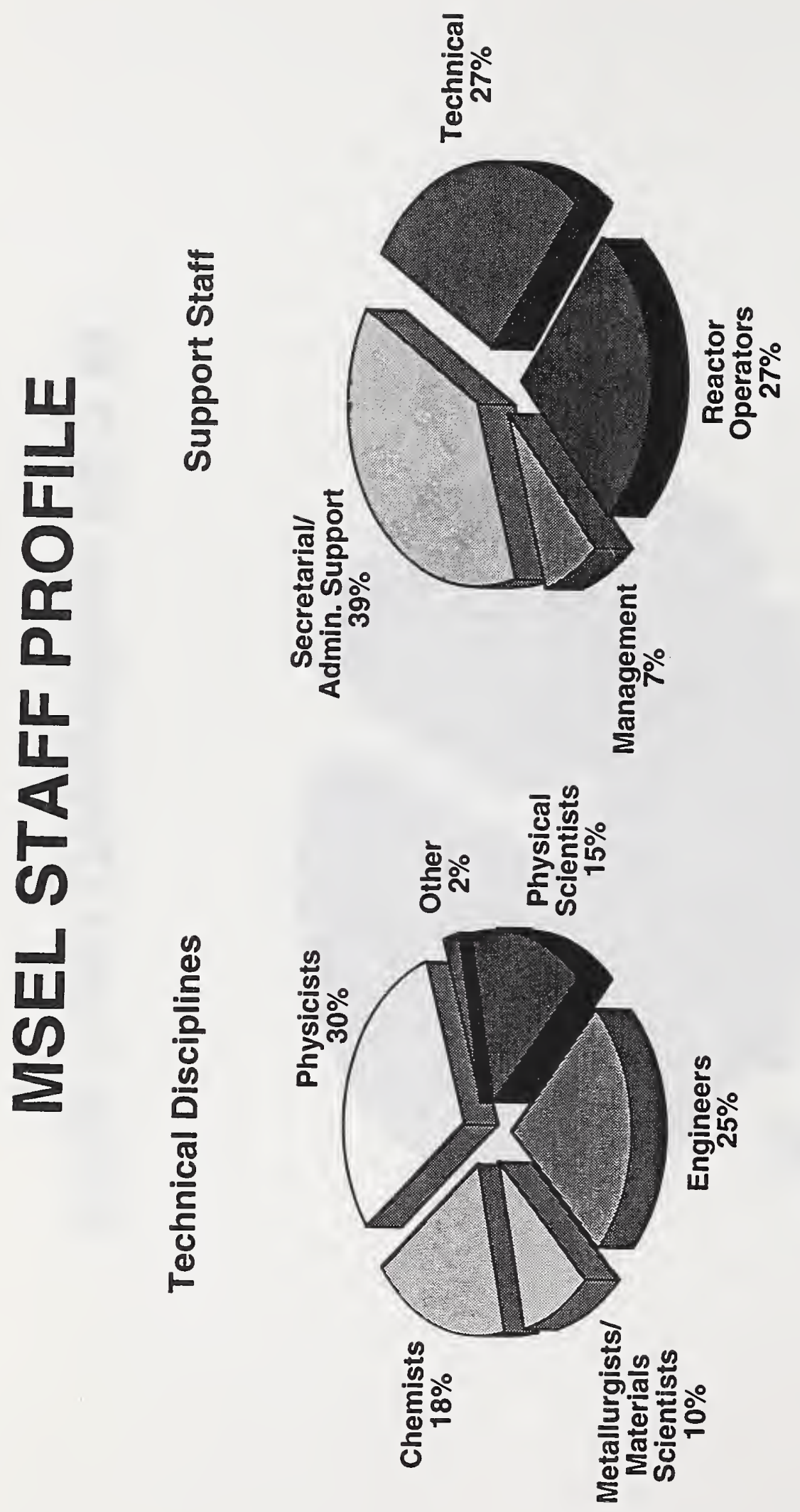

으 웅

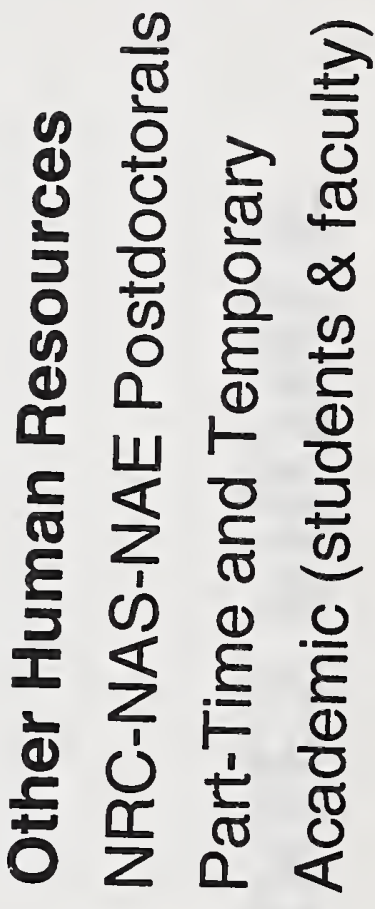
$\pm$ $\frac{\pi}{\pi}$ के $\frac{N}{n}$

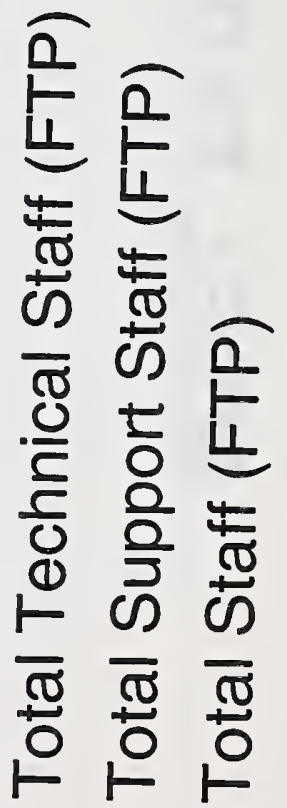




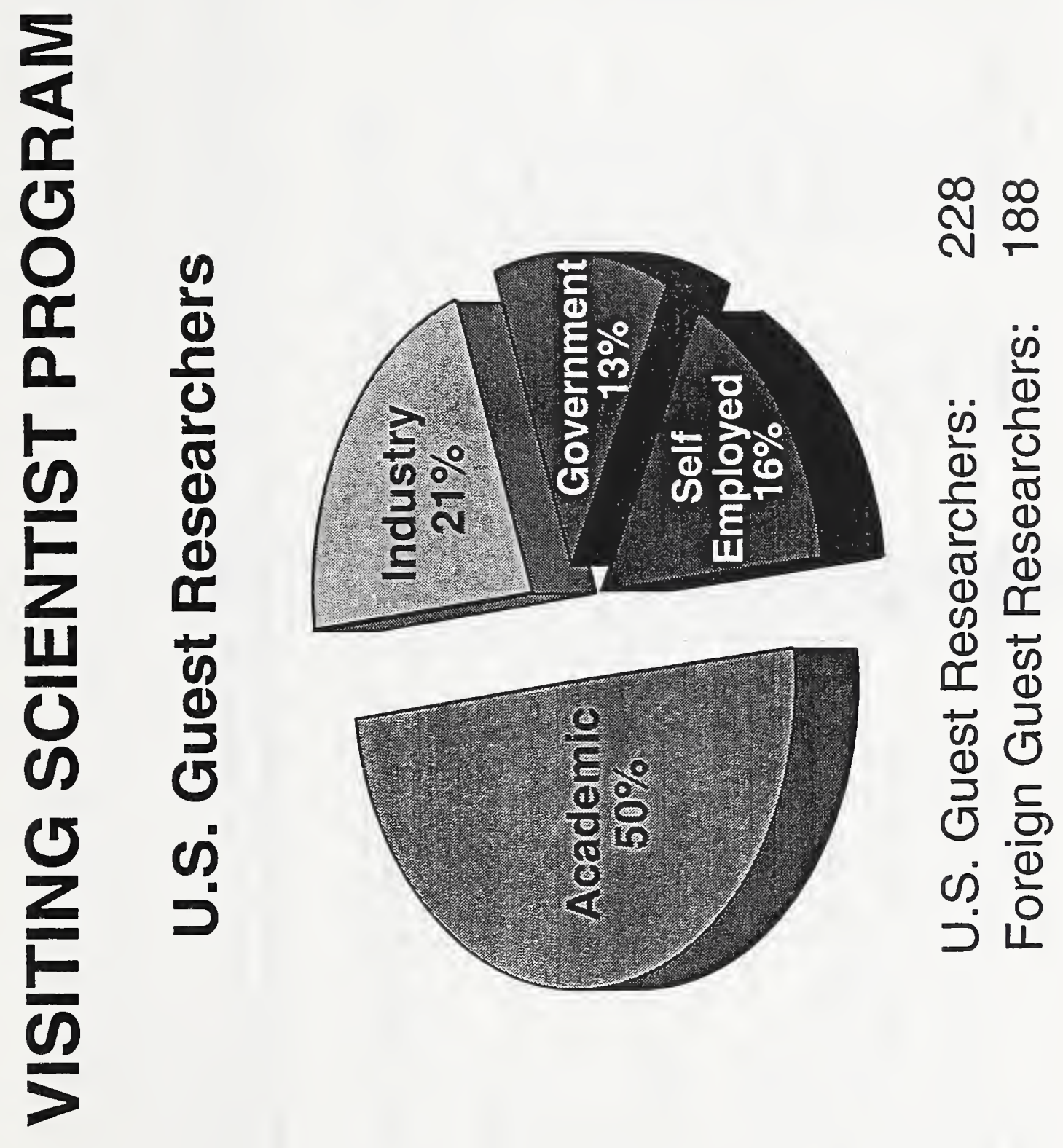




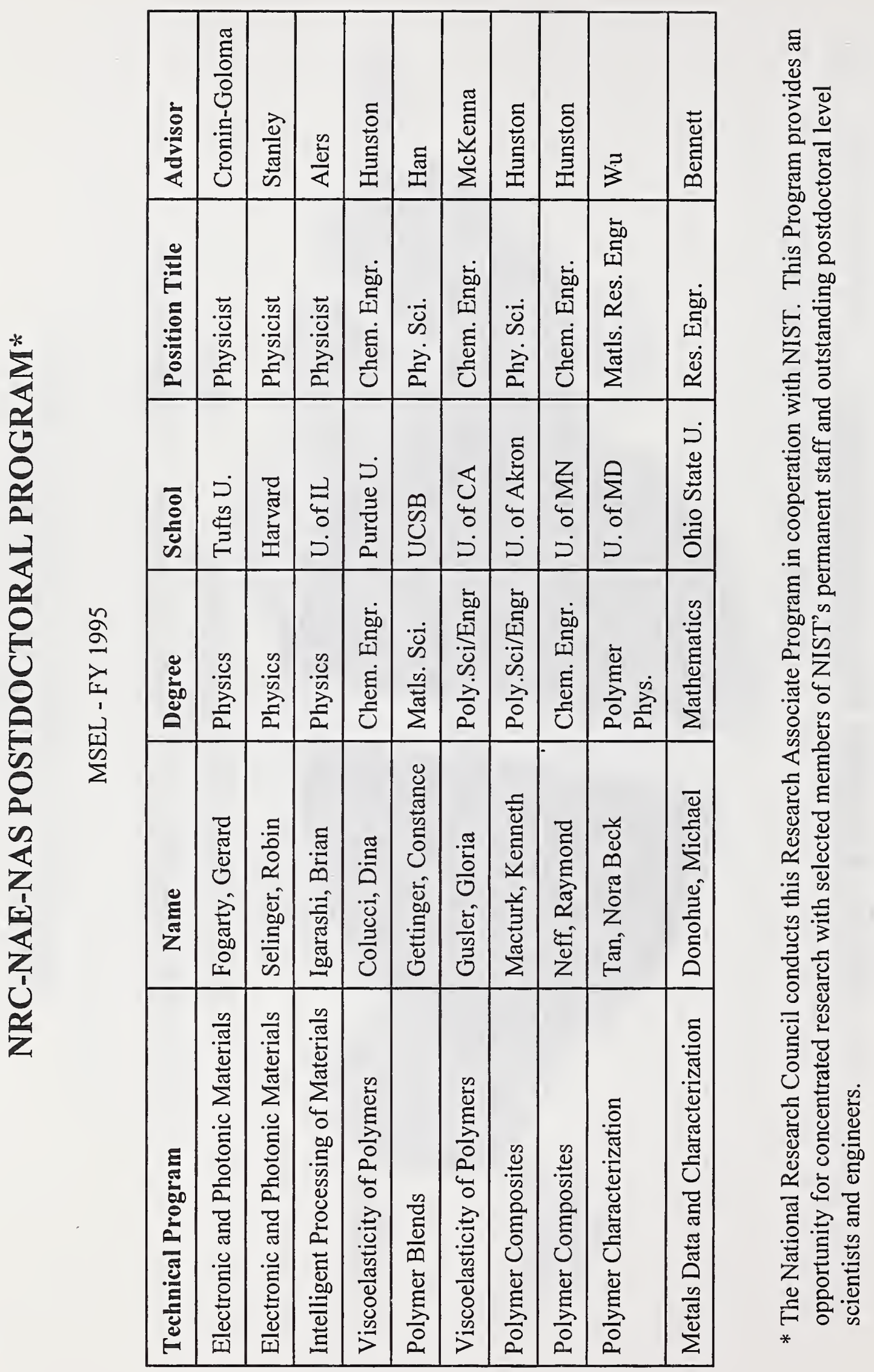


TECHNICAL PROGRAMS 



\section{PROGRAM DESCRIPTIONS}

To continue its leadership role in materials science and technology research and its ability to respond to national priorities and needs, the Laboratory carries out a variety of technical activities organized under the rubric of projects, programs or strategic thrusts. Projects are research and development activities having defined technical objectives and planned outputs addressing a specific technological barrier within a specific materials application of importance to MSEL's mission. Each program represents an array of research projects designed to collectively overcome a major technical barrier in a specific area of materials science. Strategic thrusts contain an assembly of research programs designed to accomplish the major elements of both the MSEL and NIST missions. MSEL's strategic thrusts cover three focus areas: Advanced Materials, Advanced Processing and Measurements and Standards. The Laboratory also maintains a National User Facility that it shares with its customers to attain world class, state-ofthe-art measurements of characterization and in situ process characterization of advanced materials.

\section{ADVANCED MATERLALS PROGRAMS}

\section{DENTAL AND MEDICAL MATERIALS}

The Dental and Medical Materials Program provides basic materials science, engineering, test methods, and standards to sectors of the health-care industry for the development of new or improved materials and delivery systems. The major focus sectors in this program are: (1) Development of dental restorative composites of greater durability and wear resistance, and (2) Development of metallic mercury-free alternative to dental amalgams.

Dental restorative composites are heterogeneous materials having three essential phases: (1) a polymeric matrix which comprises the continuous phase, (2) fillers of various types, sizes, shapes and morphologies which constitute the disperse phase and (3) an interfacial phase that, in varying degree, bonds the continuous and disperse phases into a unitary material rather than a simple admixture. The polymeric matrix of a dental composite is formed by free radical polymerization, under ambient conditions, of a resin which is one or more vinyl monomers, usually of the methacrylate class. Polymerization is started either by the formation of initiating radicals from chemical reduction-oxidation( redox) reactions or by photochemical redox reactions. While all three phases are important in determining the properties of the composites, this program focuses primarily on the interfacial and polymer matrix phases. Since the polymerization shrinkage that occurs in the matrix phases is one of the most commonly cited deficiencies of dental restorative composites, resources are allocated to develop high conversion, low shrinkage polymeric materials for use in dental resin and composite applications. Although only a minor component of these composites, the interfacial phase that develops from the interaction of the silane coupling agent with the polymer matrix and the siliceous filler exerts a profound effect on the properties of the composites. Because these composites are used in an aggressive, aqueous 
environment that constantly challenges the vulnerable silane mediated polymer-glass bond, understanding of this critical interfacial phase is being acquired so that strategies can be developed for its improvement.

The occupational and environmental hazards associated with the use of mercury-containing dental alloys are a recurring source of public concern. Since dental amalgams have performed exceedingly well over more than one hundred years, the development of a direct filling material still based on the common constituents of dental amalgams, other than mercury, is the objective of this focus. The approach chosen is based on three main premises: (1) the cold-welding of oxide-free silver; (2) the in-situ formation of $\mathrm{Ag}_{\mathrm{x}} \mathrm{Sn}_{\mathrm{y}}$ intermetallics by the room temperature fast diffusion of silver and tin; and (3) the homogeneous precipitation of silver by $\mathrm{Sn}(\mathrm{II})$ in solution.

Dental research directions in support of the goals are established in collaboration with the American Dental Association(ADA), the National Institute of Dental Research, and guest scientists from the U.S. Navy and the U.S. Public Health Service. NIST has hosted research associates from ADA since 1928. Currently, the ADA Health Foundation sponsors 32 research associates at NIST and their projects and accomplishments are reported in a separate publication. The collaborative relationship between that professional association and the federal government is unique, and continues to develop and transfer important new technologies to dentistry and medicine.

\section{ELECTRONIC AND PHOTONIC MATERIALS}

The objectives of the Electronic and Photonic Ceramics program are to provide data, measurement methods, standards and reference materials, models, and understanding of the fundamental aspects of processing, structure, properties, and performance of electronic and photonic materials. The program supports generic technologies in bulk and thin-film ceramics in order to foster their efficient and economical use as electronic and/or photonic materials. The research addresses the science base underlying advanced electronic/photonic materials technologies together with associated measurement methodology.

The principal activities of the program are directed toward materials for electronic and photonic technology related to data processing, storage, display, and transmission. Four aspects of this technology being addressed are modulator materials, storage-media materials, materials for microwave transmission, and material for compact, short-wavelength radiation sources to increase storage density. In the area of modulator materials, MSEL scientists are evaluating film processing methods and their relationship to properties such as electro-optic modulator characteristics. In the area of storage-media materials, scientists are addressing issues in thinfilm and bulk ferroelectric and photorefractive materials, in which the storage method involves either modification of the refractive and absorptive properties upon exposure to optical radiation or changes in material polarization by application of an electric field. Ferroelectric oxides are being studied because they possess large spontaneous polarizations, large electro-optic coefficients and large photorefractive effects. In the area of data transmission, phase diagrams 
important for the production of low-loss, thermally stable ceramics for fabrication of components to be used in microwave communication devices are being developed.

In the area of materials for short-wavelength sources, our studies are directed toward crystalline materials with large bandgaps, e.g. gallium nitride, aluminum nitride, and zinc selenide, because a large bandgap is required if a material is to emit radiation at short wavelengths. A key issue is the characterization of defects at very low concentration levels. Collaborations have been established for the purpose of providing data that will allow manufacturers to improve the quality of the materials.

\section{MECHANICAL PROPERTIES OF BRITTLE MATERIALS}

Mechanical properties are the source of some of the greatest benefits as well as the most serious limitations of ceramics. With their great strength-to-weight ratio, their relatively inert behavior in aggressive environments, and their ability to withstand much higher temperatures than metals or polymers, ceramics potentially offer major improvements for component design in a wide range of applications. On the debit side, brittle fracture, creep at elevated temperatures, environmentally enhanced failure, and the lack of techniques which can detect and quantify critical flaws before failure occurs, impede their more wide-spread uses. Problems in controlling failure of ceramics stem from three sources: lack of understanding of the failure processes, limited standard test techniques to permit inter-laboratory comparisons of material behavior, and inadequate statistical techniques for reliability and lifetime estimation. The Mechanical Properties Of Ceramics Program has components specifically addressing each of these issues.

Basic understanding of mechanical behavior of ceramiics is being investigated for both ambient and elevated temperature applications. Effects of cyclic loading and microcrack formation/coalescence are being studied for lead zirconium titanate (PZT), a technologically important actuator material. Mechanical properties and failure processes in fiber-reinforced ceramic matrix composites are being investigated as a function of both temperature and fiber loading. Residual in stresses associated with crack bridging in both fiber-reinforced composites and microstructurally toughened alumina are being measured via micro-Raman techniques. In addition, environmentally enhanced fracture remains an important subject from both an experimental and a theoretical (see Theory and Modeling section) viewpoint. At elevated temperatures, the basic mechanisms responsible for creep in silicon nitride are being investigated.

An important aspect of the program is the development of standards. New standard test techniques for hardness and toughness are being developed and tested in round-robin experiments; these will eventually lead to ASTM and ISO standards. For elevated temperatures, a new creep specimen design has been developed which concentrates more of the applied load in the gage length and reduces the chance of failure from non-gage portions of the specimen.

Finally, techniques to predict lifetimes of ceramics under constant or cyclic loading conditions 
are being developed. The nonparametric bootstrap approach to lifetime prediction is being applied to a number of materials. A parametric model to predict lifetimes of PZT under cyclic loading is also under development. This latter model does not restrict the material to environmentally enhanced fracture behavior since experimental evidence has demonstrated that other, albeit unknown, processes are also active during cyclic loading.

\section{THEORY AND MODELING}

In the past few years major advances in computation and communication have led to a revolution in the theory and modeling of materials. Huge gains in computing power and corresponding reductions in cost have led to the widespread use of computational techniques to solve materials research problems. The interdisciplinary nature of materials science has led to collaborative development of theories and software that increase our ability to predict materials properties and behavior. At NIST, researchers from different laboratories and divisions share techniques and algorithms from fields such as fluid dynamics, chemistry, and fire research in developing new tools for materials modeling.

MSEL Theory and Modeling efforts in FY95 continued their focus on the behavior and properties of materials over the range of length scales from atoms to bulk materials. On the atomistic scale, researchers have used molecular dynamics simulations to study fracture in brittle materials, and a new program to model dislocations in metals is underway. On mesoscopic length scales, simulations of phase behavior, stability, separation kinetics, and morphological evolution in alloys, polymer blends, liquid-crystalline polymers, and homopolymer/copolymer blends complement ongoing experimental efforts in the polymers, metallurgy, and reactor divisions. Simulations of such materials processing problems as, e.g., dendritic growth during solidification and spinodal decomposition of chemically reacting polymers ranged from minutelong calculations on single-processor workstations to week-long calculations on massively parallel super computers. On macroscopic length scales, finite element computer codes have been developed to model a variety of materials processes, such as injection molding for automotive parts, solder geometry in microelectronic interconnects, physical aging in composite materials, and mechanical properties of ceramic microstuctures.

The Center for Theoretical and Computational Materials Science (CTCMS) is a new initiative begun this year to develop and apply state-of-the-art theoretical and computational materials science techniques and to help industry integrate them into technology development. The center is a "distributed" or "virtual" center using electronic linkages to bring together researchers in government, academia, and industry to define and attack key materials and materials processing problems. NIST provides an infrastructure and support for the distributed members, including a World Wide Web information server. The center also established and maintains a computing facility for the use of center members at NIST and elsewhere.

The CTCMS uses workshops as the first step in defining research programs and building collaborative teams. Over the past year, CTCMS workshops have spawned ongoing programs in 
solder interconnects, Green's functions and boundary element methods, glass formation, micromagnetics, and pattern formation in polymer/liquid crystal mixtures. Other recent workshops covered fracture, rational design of advanced materials, large scale computation of realistic microstructure, theory and modeling of collective dislocations, the development of residual stresses during thermoset composites curing, the prediction of hygrothermal effects on the performance of polymers and polymeric composites, molecular beam epitaxial growth, and optimal design for materials and structures.

\section{ADVANCED PROCESSING PROGRAMS}

\section{CERAMIC COATINGS}

The Coatings program is a measurement and characterization effort which addresses the processing reproducibility and performance prediction issues associated with, primarily, thermalspray deposited ceramic coatings. The program focuses on plasma-spray-deposited ceramic thermal barrier coatings used in aircraft gas turbines and expected to be used in land-based turbines and diesel engines. Sales in the thermal-spray industry are currently valued at over one billion dollars annually, a significant portion of which is ceramic thermal-barrier coatings. Collaborations have been established with industrial organizations including Pratt and Whitney, General Electric, Caterpillar, METCO, MetTech and Zircoa as well as the Thermal Spray Laboratory at the State University of New York at Stoney Brook and the Thermal Spray Laboratory at Sandia National Laboratory. The program includes collaboration with the National Aerospace Laboratory and the National Mechanical Engineering Laboratory, both in Japan, to examine functionally gradient materials. Research is also conducted on the processing and properties of chemical-vapor-deposited (CVD) diamond films in collaboration with Westinghouse, an Advanced Technology Program (ATP) awardee, and on Physical Vapor Deposited (PVD) ceramic coatings in collaboration with Praxair, another ATP awardee.

Participants in the NIST program are located in the Ceramics, Materials Reliability and Reactor Radiation Divisions of the Materials Science and Engineering Laboratory as well as the Chemical Science and Technology Laboratory.

The approach taken in the plasma-spray (PS) research has been to build on the analytical capabilities at NIST and the material processing capabilities of collaborators. The program has the following elements:

- development of techniques for characterization of physical and chemical properties of stabilized zirconia feedstock to provide data for increased processing reproducibility as well as data required for production of a Standard Reference Material suitable for calibration of light-scattering size distribution instruments used in industry for analysis of PS powder;

- development of scattering techniques to determine the quantity, size and orientation of 
porosity and microcracks in PS ceramic coatings suitable for use in modeling the thermomechanical behavior of these materials;

- development of methods to measure chemical, elastic modulus, and thermal properties on a scale suitable for use in microstructural models of behavior;

- development of techniques to model thermomechanical behavior of thermal-barrier coatings to enable more reliable performance prediction; and

- development of techniques for accurate measurement of the thermal conductivity of PS coatings by use of the guarded hot-plate technique suitable for incorporation in ASTM standards and to provide a method for comparison with routine industrial techniques.

Research on chemical mapping of powders and microstructures is conducted in the Microanalysis Division of the Chemical Science and Technology Laboratory. Thermal property research is conducted in the Materials Reliability Division and the Reactor Division participates in both the powder analysis and scattering projects. A strong attribute of the PS coatings research is the use of common materials for which complementary data can provide a more complete understanding of processing-microstructure-property relationships.

Research is also conducted on the formation of chemically-vapor-deposited (CVD) diamond films. This research is focused on the hot-filament method utilizing graphite as a carbon source. This research has allowed the determination of basic system parameters which control nucleation and growth of the diamond film in a relatively easily controlled, inexpensive process.

\section{CERAMIC MACHINING}

Recent studies have estimated that of the total production cost, machining can account for 30 to 60 percent and sometimes even up to 90 percent for high-precision ceramic components. The high cost and sometimes uncertain reliability at times associated with machining damage in ceramic components in comparison with their metallic counterparts are often cited as impediments to the wide spread use of these materials. The goal of the NIST Ceramic Machining Program is to assist the U. S. industry, through a joint research program, in the development of precision machining technology for the manufacture of reliable and costeffective products made from advanced ceramics. In addition to research within MSEL, joint research is conducted with the Precision Engineering Division, Automated Production Research Division, and Statistical Research Division. The specific projects address Grinding Optimization, Machinability Database, Nano-Precision Grinding, Mechanisms of Material Removal, Characterization of Machining, Damage, and Chemically Assisted Machining.

The research in this program is conducted in cooperation with ceramic producers and users as well as the academic research community and government laboratories. Much of this research is conducted as part of the NIST Ceramic Machining Consortium, consisting of 20 members from 
industry and academia, and which provides guidance on manufacturing issues and near term implementation of program results. Current research materials include those intended for structural applications, such as silicon nitride, and dental materials, such as machinable glass.

\section{CERAMIC PROCESSING}

Processing of ceramic powders to the green and sintered states is a major component in the production of ceramics with high degrees of reproducibility and cost-effectiveness. Several programs have been initiated in a number of countries involved in advanced ceramics to address these issues. Technical issues affecting the cost-effective manufacturing are synthesis of novel powders that have tailored properties, repeatability and reproducibility in the measurement of powder properties, procedures for characterization of secondary properties of powders, powderaqueous environment interactions, and sintering behavior of green ceramics.

The program on ceramic processing is designed to address some of these issues with a focus on improvement of measurement quality in ceramic powders processing. This is accomplished by providing the U.S. ceramics community the ability to control ceramic powder properties so that cost-effective manufacturing can be achieved. The current program continues to emphasize structural ceramics with application of silicon nitride to automotive engines. The specific elements of the program are as follows:

- $\quad$ ceramic powder characterization techniques, measurement science, sensors and models for intelligent processing, standard methods and standard reference materials;

- $\quad$ powder processing science to understand interrelationships between powder characteristics and their processing environment; and

- novel processing and synthesis methods as applied to nanosize and ultra-pure powders.

Ceramic processing projects address the development of standard procedures, standard reference materials, improving the scientific basis of powder dispersion measurements in slurries, overall improvement in measurement accuracy, and leadership in national and international standardization activities including the ISO and ASTM. The powder characteristics of interest include physical and surface chemical properties, and phase composition. In addition, grainboundary characterization, and crystallographic texture investigations are carried out using advanced characterization tools. In powder processing, our efforts have been focused around high-energy agitation milling of powders, textured $\mathrm{Al}_{2} \mathrm{O}_{3}$ microstructure, and hot-isostaticpressing of silicon nitride.

\section{INTELLIGENT PROCESSING OF MATERIALS}

Intelligent processing of materials (IPM) is the conversion of materials into value-added products using model-based control of processing variables. Information for real-time process control is 
provided by on-line sensors which measure material characteristics and/or processing conditions. Intelligent processing will enable industry to economically produce materials with improved quality, consistent properties, and enhanced functionality. The IPM Program makes important contributions to three MSEL strategic thrusts: advanced processes, advanced materials, and measurement technology.

The IPM concept is the principal approach used to achieve the MSEL goal to "Foster the development and implementation of technologies for advanced processing of materials." The central elements of IPM are 1) process understanding expressed in terms of a process model, 2) real-time information on processing parameters and material condition obtained with on-line process sensors, and 3) a model-based sensing and control strategy to achieve the desired characteristics in the finished product. IPM projects advance each of the elements, and joint projects with industry are integrating these elements into improved processing capabilities.

The IPM Program is an important contributor to the MSEL goal to "Foster the use of advanced materials in commercial products." Advanced materials are materials with microstructures which are designed and controlled to provide superior properties and performance for specific functions. Microstructural control is perhaps the most important application of IPM. The idea is to model microstructural evolution during processing, sense microstructural changes in real time, and use a model-based control strategy to achieve the desired microstructure in the finished product. Microstructural consistency is essential to the commercialization of advanced materials because it assures reliable properties and performance of the material.

The IPM Program also contributes to MSEL's measurement technology goal. A major focus of the IPM projects is process sensors, which our industrial collaborators repeatedly identify as a crucial need. Sensor technology is a core competence of MSEL which has its roots in sensor development for nondestructive evaluation of materials. Unique MSEL capabilities are being used to measure thermophysical properties at elevated temperatures; these data are combined with model enhancements and then incorporated in industrial software for metal casting. In addition, specialized measurement capabilities such as nuclear magnetic resonance and small angle neutron scattering are used to understand microstructure/morphology evolution in ceramics and polymers.

\section{METALS PROCESSING}

The properties of metals and their alloys depend strongly on their processing history. The conditions under which materials are processed and fabricated into useful items determine the distributions of phases, grains, and defects in the final products. These distributions are crucial in determining the alloy strength, ductility, magnetic response, homogeneity, and other properties important for commercial applications. The Metals Processing Program focusses on measurements and predictive models needed by industry to provide improved process control, develop improved alloy properties, tailor material properties for particular applications, and reduce costs. 
Major successes in applying measurements and modeling to processing applications already have been achieved, notably in interactions with the aerospace, powder metallurgy, and electronic industries. For example, cooperative research and development projects with industry (Crucible Compaction Metals, Fluxtrol Manufacturing) have resulted in significant improvements in process control for steel and superalloy powders. Moreover, predictive models for solidification and microstructural evolution during processing have been incorporated by industry into design systems for casting of aerospace alloys and production of defect-free electronic materials, helping to reduce rejection rates arising from defective parts. Current measurement and modeling activities in this program emphasize work on rapidly solidified steels, aerospace castings, thin films, intermetallic alloys and electronic materials. Frequent interactions and collaborations with industrial producers are maintained, including participation in industriallyoriented consortia and ASTM. Standard reference materials, such as the homogeneous standard reference materials currently being produced by rapid solidification, which are unobtainable by other means, are another important output of the current work. Measurements and predictive models for processing being pursued in this program are of three kinds:

- Measurements and models are developed to help design materials production processes, such as measurements and evaluations to provide alloy phase diagrams, which are the roadmaps alloy designers use to predict the alloy phases that can be produced under specific processing conditions. These evaluations are playing key roles in NIST collaborations with industrial consortia on electronic solders and casting of superalloys for aerospace applications.

- Measurements are made under dynamic conditions to monitor, in real time, properties of materials while they are actually being produced and to determine difficult-to-measure process parameters while the process is occurring. In collaboration with the NIST program on intelligent processing of materials, special fast-response sensors, simulations and imaging techniques have been developed for this purpose, and workshops have been held to transfer these techniques to industry. Here, dynamic models of the process are important both for design of manufacturing procedures and for applications of real time feedback and control.

- To evaluate the adequacy of process models, it is important to measure the properties of the final materials and relate them to the process conditions. A current emphasis in this respect is on relating impact resistance and corrosion resistance of rapidly solidified nitrogenated stainless steels to processing conditions and alloy microstructure. Norfolk Southern (railroad switches), DoD/ARPA (armor applications), and Crucible Materials Corporation (corrosion resistant alloys) have collaborated with NIST in various aspects of this work.

In all of this work, the goal is to help U.S. industry apply measurements and predictive modeling to produce improved materials at reduced cost. 


\section{POLYMER BLENDS}

Applications of polymer blends and alloys have enjoyed steady growth over the last decade in terms of market share, consumption and employment within the plastics industry. This growth has challenged materials suppliers to respond quickly to customer needs by reducing their new product development cycle. In assessing these requirements, a 1992 article in Plastics Technology expressed the need in the 1990's to "scientifically understand ways to make resins compatible and create predictable stable morphologies", in contrast to the largely unsuccessful trial and error "empirical blending frenzy" of the 1980's.

The Polymer Blends and Processing Program began its efforts in the mid-1980's with clear scientific goals to establish expertise in static and kinetic aspects of phase behavior in polymer blends, effects of shear flows on mixing and separating, and reactive processing to promote compatibility. Current program objectives use the knowledge base and measurement expertise to develop tools needed by industry to process polymer blends more effectively. Accordingly, the program works on development of measurement methods using fluorescence, light scattering, neutron scattering, and microscopy to aid in monitoring polymer blend processing. In addition, two NIST/Industry Consortia have been established to facilitate interactions and transfer measurement technology in the areas of polymer blends and processing.

The objective of the first consortium is to develop new measurement techniques based on optical methods to monitor important polymer processing parameters. Two areas of measurement development are being stressed in this program: real-time measurements of polymer rheology and temperature. Our industrial consortium partners are: $3 \mathrm{M}$ Co., Dow Chemical Co., DuPont Co., Rohm and Haas Co., and Dynisco (Flow Vision):

The second consortium is in the general area of polymer blends, and includes: Aristech Chemical Corp., Armstrong World Ind., Inc., Goodyear Tire \& Rubber Corp., Raychem Corp., Rohm and Haas, Sandia National Laboratories, 3M Company. In addition Exxon participates through a separate CRADA. Work in this consortium during the past year focused primarily on in-situ characterization of mixing/separating processes by shear and on interfacial modification and blend compatibility by graft or block copolymers. Collaborative efforts with individual consortium companies serve to transfer the NIST expertise and capability in measurement technology as well as to provide an emphasis on issues of practical importance to industry.

\section{POLYMER COMPOSITES}

The polymer composites program seeks to facilitate the introduction of light-weight, corrosionresistant composite materials into commercial applications by expanding the essential science base and generating test methods, reference data, and standard materials. The outstanding properties of composites mean they can be used to make products that are superior and more competitive in international markets. Industries as diverse as transportation, construction, marine, off-shore oil, medical devices, and sporting goods can benefit significantly from the use of these materials. For this to happen, however, two barriers must be addressed: the lack of 
rapid, reliable, cost-effective fabrication methods; and the poor understanding and predictive capability for durability. These barriers were identified a series of industry workshops, exchange visits, and consultations. In response to these challenges, the composites program initiated two tasks: one on processing science and the other on long-term performance. The automotive industry has a strong influence on the work since this market has the biggest potential for near term impact. Nevertheless, the program also interacts with companies interested in off-shore oil platforms, infrastructure, aerospace, and a variety of other applications.

The goal in the Processing Science Task is to develop the technology required to monitor, understand, model, and control the events that occur during composite fabrication. The program's primary interest is in liquid composite molding (LCM) since this fabrication method is of great interest to all industry sectors and is the consensus choice of the automotive industry as the method with the most promise for making structural automotive parts. The approach in this task involves three steps. First, measurement tools are developed and used to characterize the material properties that control processing, for example, permeability. Second, sophisticated process simulation models are formulated to analyze the effects of processing parameters rapidly and inexpensively so they can be optimized. Finally, process monitoring sensors are developed and utilized to provide feedback for verification and improvement of the simulation models and to help develop the technology for on-line process control. The current activities in this Task involve five Projects including a major industry-university-government program sponsored by the Advanced Research Projects Agency.

The work on performance focuses on composite characterization tools and environmental durability. The goals are: (1) to develop measurement methods that can determine the state of the material, (2) to identify the chemical and physical mechanisms of environmental attack, and (3) to formulate reliable predictive models for long term behavior. There are five projects, two on characterization and three on environmental durability. The first characterization project focuses on the development and understanding of non-destructive evaluation (NDE) methods for composites. Uncertainty about the reliability of post fabrication and in-service inspection of composites continues to be an important challenge. The second characterization project investigates the use of ultrasonics to evaluate composite materials. Important aspects of this work are the determination of elastic constants and the use of ultrasonic data to estimate microstructural features.

The environmental durability projects focus on glass fiber materials since they are the primary candidates for automotive applications. Work is beginning on graphite reinforced composites since these systems are important for marine and infrastructure applications. The usual approach in durability studies is to characterize the behavior of composite samples exposed to various environmental conditions. Because a composite is such a complex system, however, the interpretation of the data is difficult. The work here uses two approaches to address this problem. First, composites are formulated with systematic variations in constituents and processing conditions. A comparison of durability data for the various samples can then provide insight into the possible sources of the differences in behavior that occur. Second, durability is 
measured on the individual components (i.e., the resin, the fiber, and the fiber-matrix interface) as well as the full composite. An understanding of how the component responses contribute to the behavior of the composite provides additional insights into the degradation mechanisms.

\section{MEASUREMENTS AND STANDARDS PROGRAMS}

\section{BIOTECHNOLOGY}

The Neutron Scattering Facilities at the NIST Research Reactor offer a unique opportunity in the US for studying the structure and dynamics of biological macromolecules and biomimetic systems as a function of chemical or biological environment. Two $30 \mathrm{~m}$ small-angle neutron scattering (SANS) instruments and reflectometers provide the country's best combined capabilities for surface and structural studies. Both SANS and reflectometry are well-suited for in situ structural studies of macromolecules in solution ranging in size from $1 \mathrm{~nm}$ to $100 \mathrm{~nm}$. In addition, a wide range of dynamic processes encompassing the $10^{-7}$ to $10^{-12} \mathrm{~s}$ time scales will soon be accessible with the completion of three state-of-the-art neutron spin-echo, highresolution time-of-flight and back scattering spectrometers. These techniques provide information on macromolecular dynamics which is complementary to, and in many cases more direct than, that obtained from NMR and electron spin resonance and which can be directly compared with molecular dynamics computer simulations. In this program, both structure and dynamics studies are being pursued, using this unique variety of measurement capabilities, to probe structure-function relationships in macromolecules and other biologically and technologically important systems. The program is being carried out with close collaboration and support from NIST's Biotechnology Division.

\section{ELECTRONIC PACKAGING AND INTERCONNECTION}

The U.S. microelectronics industry, valued at over $\$ 300$ billion in 1995 , is confronted with technological changes at an unprecedented pace and urgency. This is partially due to increased consumer expectations, rapid product evolutions, and heightened international competition. In response to these pressures, the U.S. semiconductor and module interconnection industries, representing combined sales of over $\$ 54$ billion in 1995, have taken the landmark steps of developing technology roadmaps. These two roadmaps, entitled The National Technology Roadmap for Semiconductors and The National Technology Roadmap for Electronic Interconnects, produced by the Semiconductor Industry Association and the Institute for Interconnecting and Packaging Electronic Circuits, respectively, identify roadblocks and performance characteristics for the manufacture of globally competitive products. Significant portions of these roadmaps address the packaging and interconnection of semiconductor devices, a technology which now amounts to over one-third the delivered cost of integrated circuits.

To assist this strategic and rapidly growing U.S. industry, the NIST Materials Science and Engineering Laboratory has embarked on a new program in electronics packaging and interconnection that addresses industry's most pressing challenges surrounding the utilization of 
advanced materials and material processes. With a specific mission to develop and deliver to U.S. electronics and electronic materials industries measurement tools and data for materials and processes used in semiconductor packaging, module interconnection and component assembly, the strategy used to implement this program is based upon three primary needs.

- Develop techniques and procedures for making in-situ, in-process and in-use measurements on materials and material assemblies having micrometer- and submicrometer-scale dimensions.

- $\quad$ Record and quantify the divergence of material properties from their bulk values as dimensions are reduced and interfaces are approached.

- Develop fundamental understanding of materials needed for future packaging, interconnection and assembly schemes.

This strategy is the outgrowth of two industry-led workshops conducted at NIST. The first, conducted in 1990, set the course for the Laboratory's emerging plans in packaging, interconnection and assembly. The second, conducted in early 1994, identified a series of crosscutting barriers, critical technical challenges and opportunities for NIST in materials science and engineering deemed most needed by the U.S. microelectronics industry. The results of this workshop are contained in NISTIR 5520, Metrology and Data for Microelectronics Packaging and Interconnection.

Now in its second full year of funding, the program has in place a portfolio of projects involving the talents and operations of metallurgists, polymer scientists, and materials reliability specialists. During this period, the MSEL program has developed numerous single-company and consortia-based collaborations that involve over twenty-three U.S. companies; fifteen universities; four other government agencies or laboratories; and eight consortia, standards bodies and associations. These collaborations have resulted in forty-six technical publications, sixteen of which were published in 1995, and numerous individual accomplishments that directly impact industry's research and development needs.

\section{EVALUATED MATERIALS DATA}

The objective of the Data Technologies program is to develop and facilitate the use of evaluated databases for the materials science and engineering communities. Both research- and application-directed organizations require readily available evaluated data to take advantage of the large volume of materials information developed on public and private sponsored programs. This information, particularly numeric data, is available in an ever increasing number of publications published worldwide. The necessity to consolidate and allow rapid comparison of properties for product design and process development underlies the database projects.

Evaluated Data projects are conducted in cooperation with the NIST Standard Reference Data 
Program Office and include compilation and evaluation of numeric data as well as recently initiated efforts directed at more effective distribution and use of data.

Database projects in MSEL include:

- Phase Diagrams for Ceramists (PDFC), conducted in cooperation with the American Ceramics Society;

- the Structural Ceramics Database (SCD), a compilation of evaluated mechanical and thermal data for nitrides, carbides, and oxides of interest to engineers and designers;

- a ceramic machinability database, coordinated with the Ceramic Machining Research Program;

- a high $\mathrm{T}_{\mathrm{c}}$ superconductivity database developed in cooperation with the Japanese Agency for Industrial Science and Technology (see superconductivity);

- development and implementation of the STEP protocol for the exchange of materials data, under the auspices of the ISO 10313 activity;

- the NACE/NIST Corrosion Performance Database developed to provide a means to select structural alloys for corrosive applications; and

- the Crystal Data Center which provides fundamental crystallographic data on inorganic materials.

These projects are developed with the cooperation of the materials community and complement various research programs.

\section{HIGH TEMPERATURE SUPERCONDUCTIVITY}

A significant program in high- $\mathrm{T}_{\mathrm{c}}$ (critical transition temperature) superconductivity is being conducted in MSEL and other Laboratories at NIST. The primary focus of the MSEL Program is on bulk superconducting materials for wire and magnet applications. In carrying out this program, researchers in MSEL work closely with their counterparts in other NIST Laboratories, and collaborators in U.S. industry and other National Laboratories.

The primary thrusts of the program are as follows:

- $\quad$ Phase equilibria - Work is being performed in close collaboration with the U.S.

Department of Energy (DOE) and its national laboratories to provide the phase diagrams necessary for processing these unique ceramic materials. A prime objective is the development of the portions of the phase diagram for the $\mathrm{Pb}-\mathrm{Bi}-\mathrm{Sr}-\mathrm{Ca}-\mathrm{Cu}-\mathrm{O}$ system 
relevant to production of the high $T_{c}$ materials.

- $\quad$ Flux pinning - This project makes use of a unique magneto-optical imaging facility to examine flux pinning in a variety of materials. Much of this work is being conducted in collaboration with American Superconductor Corporation. In addition techniques for better interpretation of magnetic measurements are being developed.

- Damage mechanisms - Work is being carried out under a joint CRADA (cooperative research and development agreement) with American Superconductor Corporation as part of the "Wire Development Group" which involves a number of DOE National Laboratories and the University of Wisconsin to elucidate the effects of strain on the loss of current in superconducting wires. The primary tool being employed is the use of microfocus radiography available at the NIST beamline at the Brookhaven National Laboratory.

- Database - A high- $\mathrm{T}_{\mathrm{c}}$ superconductor database has been developed in collaboration with the National Research Institute for Metals (NRIM) in Japan. The High-Temperature Superconductor Database (HTSD) includes evaluated open-literature data on numerous physical, mechanical, and electrical properties of a variety of chemical systems. The first version of the database is now for sale by the Office of Standard Reference Data.

- Crystal structure - Thermal neutron diffraction techniques and profile refinement analyses are being utilized to investigate crystal and magnetic structures, composition, and crystal chemical properties. This research is being carried out in collaboration with a number of industrial and university experts.

\section{METALS DATA AND CHARACTERIZATION}

Basic data describing the properties of metals and advanced materials based on metals form an important component of the technological infrastructure which NIST supports. Information of this kind is essential to the understanding of the behavior of metals in different conditions and to the effective design of structures and devices containing metals. The measurement base is an MSEL mission strategic thrust.

This program is focussed on the development of techniques to measure various properties of metallic materials and the acquisition of data of technological significance. It includes activities involving measurements of mechanical, magnetic, and optical properties which impact a number of different technology sectors. For instance, in collaboration with the Copper Development Association, the mechanical behavior of lead-free plumbing solders is being investigated to provide the comprehensive and reliable database needed to establish internal working pressure standards for drinking water pipe joints. In contrast with these traditional measurements involving a widely used material, high speed optical techniques are being developed in another project to measure selected thermophysical properties of solid and liquid materials at high 
temperatures. The goals of this work are to generate accurate bench-mark data on selected key materials and to develop new high-temperature thermophysical standards. In other work involving a collaboration with ALCOA and USCAR, models are being developed and verified for the press-and-sinter and powder forge processes for metal matrix composites. The goal of this work is to develop lightweight materials for automotive applications. In the area of characterization, a technique is being developed which visualizes stress fields in opaque materials using the acoustic microscope. Work in the past year has included collaborations with DuPont, Libby Owens Ford, and Sonix.

\section{NANOSTRUCTURED MATERIALS}

Nanostructured Materials are a new class of materials which provide one of the greatest potentials for improving performance and extended capabilities of products in a number of industrial sectors, including the aerospace, tooling, automotive, recording, cosmetics, electric motor, duplication, and refrigeration industries. Encompassed by this class of materials are multilayers, nanocrystalline materials and nanocomposites. Their uniqueness is partially due to the very large percentage of atoms at interfaces and partially to quantum confinement effects.

One critical need for their implementation is their characterization and measurement science which is the focus of the NIST program. For many properties, it is not known whether the exciting novel behavior found in these new materials is due to new physics or to a logical extension of large-size behavior to small dimensions. Examples include the deformation and fracture behavior (wherein it is not known whether dislocations even exist in these materials), optical characteristics (wherein uncertainties exist in whether the properties are due to interface or quantum mechanical effects), magnetic properties (wherein it is not known what magnetic domains even look like in nanostructured materials or how they move in response to a magnetic field), and thermal properties (wherein the propagation of phonons through interfaces is poorly understood). Consequently, implementation of this new type of material into marketable products is significantly delayed.

NIST is providing the measurement science to answer these critical unknowns. Important needs also include the identification of preparation methods for industrial-size quantities of material, extension of the capabilities of conventional measurement tools to the nanometer-size scale, and the development of consolidation methods which still retain the nanometer grain size of the initial nanocrystalline powders. For multilayers, understanding the development of epitaxy and control of both composition and interdiffusion at the interface are of critical importance.

By experimentally addressing these issues, by bringing together the industrial and scientific communities through the organization of workshops and conferences in the area, and by the development and preparation of appropriate standards, NIST acts to accelerate the utilization of these materials by the industrial sector. In addition, collaborations established in the area with Xerox, General Motors, Nanophase Technologies, Pratt and Whitney, Caterpillar, LockheedMartin, Hewlett Packard, IBM, Seagate, and Motorola Corporations, for example, enable NIST 
to leverage its activities with the much larger, but complementary, capabilities of other organizations.

\section{NEUTRON CHARACTERIZATION}

This program encompasses the basic and applied research efforts and neutron scattering method development centered on the Neutron Condensed Matter Science Group in the Reactor Radiation division. Group scientists and visiting researchers lead broad-based mission research in chemistry, solid state physics, materials science and biology, often in collaboration with other divisions in MSEL and the Biotechnology, Surface and Microanalysis, Thermophysics, and Analytical Chemistry divisions in CSTL), and with over 100 universities and industries from all over the U.S. (and the world). Group scientists also develop and maintain state of the art capabilities and instruments as a national resource for cold and thermal neutron scattering research, including scientific leadership and oversight in the development and use of 10 experimental stations in the Cold Neutron Research Facility.

Current areas of emphasis in the multidisciplinary research program include: studies of the structure and excitations of high technology magnetic and superconducting materials, thin films and multilayers; crystallographic analysis of the atomic and molecular arrangements in catalysts, ceramics, superconductors, ionic conductors, and fullerites; sophisticated neutron diffraction analysis of residual stress and texture which affect properties and performance of technologically important alloy, ceramic and composite structures and components; studies by neutron reflectometry and small angle scattering (SANS) of macromolecular and microstructures in materials and of molecular and magnetic surfaces and interfaces; inelastic neutron scattering studies of molecular bonding states and dynamic processes in chemical catalysts, sieves, polymers and battery materials, and molecular scale curing processes in cements; and studies of biomolecular structure and dynamics in proteins, lipid bilayers and membranes.

\section{NONDESTRUCTIVE EVALUATION}

Nondestructive evaluation (NDE) is the determination of product quality using test methods which do not damage the product. At MSEL, the NDE Program is directed to the development of model-based methods of physical measurement which characterize the internal geometries of materials, such as defects, microstructures, and lattice distortions. The goal of NDE is to convert these measurement methods into sensors suited for production line and in-service measurements of materials quality and serviceability. The NDE program makes important contributions to two MSEL strategic thrusts: advanced materials and measurement technology.

A primary focus of the NDE Program is microstructural characterization of metals and alloys, composite materials, and engineered surfaces. The idea is that models relate microstructure and physical properties. Thus, by measuring quantities related to physical properties, the salient microstructural features can be ascertained. For example, sound velocity is related to elastic properties, and thus, ultrasonic measurements can be used to characterize fiber-orientation 
distributions in composites or texture in metals. These model-based measurements enable industry to replace microscopy with nondestructive methods for the microstructural characterization needed to assure the quality of advanced materials.

The NDE Program is making significant contributions to measurement technology and materials modeling. Our primary emphasis has been on acoustic methods. We have worked with industry to commercialize advances in noncontact ultrasonics, wave-form based acoustic emission, composites NDE and nonlinear ultrasonics. Research is also underway in magnetic, thermal and radiographic techniques. Modeling advances include Green's function methods for wave propagation in anisotropic materials, obtaining elastic constants from resonance spectra, and determining texture based on ultrasonic measurements.

\section{POLYMER CHARACTERIZATION}

The Polymer Characterization program provides measurement methods, data, and standard reference materials needed by U.S. industry, research laboratories, and other federal agencies to characterize polymers for processibility, properties, and performance. Molecular weight and molecular weight distribution are the molecular characteristics of polymers that most affect their processing, properties and performance. Properties and performance may also vary widely depending on the solid state structure formed during processing. Therefore, the focus of the program is on techniques that measure molecular weight, its distribution and the solid state structure of polymers.

Primary methods employed for molecular weight are dilute solution light scattering and osmometry; chromatographic techniques, which require calibration by standards of known molecular mass, provide information on molecular weight distribution. Recent activities seek to exploit recent advancements in mass spectrometry using mass assisted laser desorption ionization (MALDI) to determine molecular weights of synthetic polymers. Other spectroscopic methods, solid state nuclear magnetic resonance (NMR) and infrared, as well as x-ray diffraction are developed and applied to elucidate the solid state structure of polymers.

The polymer industry and standards organizations assist in the identification of current needs for standard reference materials. Based on these needs, research on characterization methods and measurements are conducted leading to the certification of standard reference materials. Standards are produced for calibration of gel permeation chromatographs, the principal method used by industry for assessing molecular weight and molecular weight distributions, and melt flow standards that are used in the calibration of instruments used to determine processing conditions for thermoplastics.

\section{STANDARD REFERENCE MATERIALS}

The NIST Standard Reference Materials Program serves as the nation's primary source of reference standards used to develop accurate methods of analysis, calibrate measurement systems 
and assure the long-term adequacy of measurement assurance programs. The aim is to assist industry, science, and academia to achieve the level of product conformance and measurement quality that meet national and international commerce and trade.

As the world commerce and trade markets have become more global, customers are using SRMs more and more. All data derived from measurements in which SRMs are part of the measurement system have the capability of being traceable to a common and recognized set of standards and, consequently, the compatibility of data can be realized.

The technical staff of the Materials Science and Engineering Laboratory produces a series of standards for materials suppliers and users that are key elements in assisting this industry to develop and/or improve its competitive edge in the global arena. MSEL designs, develops and produces many SRMs related to ceramics, polymers, metals and related materials. These SRMs are routinely employed in the production and processing of materials. Many projects are conducted in cooperation with applicable industries and are an integral part of the Laboratory's research efforts.

\section{SYNCHROTRON RADIATION}

The Materials Microstructural Characterization Group in the Ceramics Division operates two xray experimental stations at the National Synchrotron Light Source (NSLS), where researchers from NIST, industry, universities and other government laboratories carry out state-of-the-art measurements on ceramic, semiconductor, photonic, metallurgical, biological, and other materials of high scientific or technological interest. X-ray measurement capabilities include ultra-small-angle scattering (USAXS), topography, diffraction-imaging microscopy, $\mathrm{x}$-ray absorption fine structure spectroscopy (XAFS), standing-wave $x$-ray scattering (SWXR), and reaction-kinetic surface science measurements.

The range of studies performed over the past year include processing-microstructure relationships in plasma-sprayed ceramic deposits, sintering of nanostructured ceramics, straininduced microcracking in high- $T_{c}$ superconducting composite tapes, grain-size/pore-size trajectories within ceramic microstructures during processing, diffraction imaging of $\mathrm{ZnSe}$, strain and bond distortion in ultra-thin semiconductor films, and the determination of atomic-scale and molecular-scale structures at technologically important surfaces and interfaces.

In addition, as part of a national facility, time on the NIST instruments at the NSLS is made available to qualified researchers based on peer-reviewed proposals. In the past year, researchers from chemical, aerospace, energy and materials production industries as well as from NIST laboratories, other government laboratories and universities have completed experiments that could not have been performed elsewhere in the United States. The long-term goal of research at these facilities is to enable researchers to address basic issues so that U.S. manufacturers can provide superior materials based on structural information not available elsewhere. 
Looking toward the future, the NIST Materials Science and Engineering Laboratory (MSEL) has entered a Collaborative Access Team (CAT) agreement with the University of Illinois, Oak Ridge National Laboratory, and U.O.P. Corporation, the purpose of which is to build and operate $\mathrm{x}$-ray instruments on sector 6 at the Advanced Photon Source (APS) now under construction at the Argonne National Laboratory. The CAT is called UNI-CAT in recognition of the University, National Laboratory, and Industrial components of this team. This partnership is particularly attractive to us at NIST because there is significant overlap with current and future NIST interests.

The APS will offer a $10^{2}-10^{4}$ increase in brilliance compared to the best synchrotron $\mathrm{x}$-ray sources of today. In the years to come, the APS will supplant the NSLS as this nation's premier $\mathrm{x}$-ray source. The APS beam lines now being built by UNI-CAT incorporate the newest technology which will not only enable NIST scientists to improve significantly our real-time xray microscopy, ultra-small-angle $\mathrm{x}$-ray scattering, in-situ $\mathrm{x}$-ray topography and EXAMS capabilities, but will also offer opportunities for cutting-edge experiments in structural crystallography (and time-resolved structural scattering), surface/interface scattering, diffuse scattering, and magnetic scattering. NIST scientists will extend our present portfolio of characterization capabilities to include an even wider range of materials measurement of importance to materials scientists and to U.S. industry.

\section{VISCOELASTICITY OF POLYMERS}

The goals of the Viscoelasticity of Polymers Program are motivated by the rapid growth in polymers in engineering applications, including wholly new uses. The efficient development of new applications for polymers requires improved design methods for estimating dimensional stability and long term performance. Technical factors include dimensional tolerances, processinduced residual stresses and fatigue behavior in complex thermal, stress and humid environments during use.

The goals of the Viscoelasticity of Polymers Program are to develop measurement strategies that produce mechanical properties data in efficient ways and concurrently to build methodologies that can be applied in the design and development of finished polymers. The approach uses the theoretical frameworks of continuum constitutive equations and micro- to meso-scale physical models to interrelate the mechanical responses under different loading conditions and to test model predictions using available measurement methods. The work involves the first major effort to measure the mechanical and rheological responses of a single class of solid polymer in multiple geometries of deformation and modes of loading as well as in different temperature histories. The combination of experiment and modeling results in both improved models and the development of new experimental methods for measuring material property parameters. Furthermore, the measurement and modeling requirements are renewed continuously by coordinating the efforts through collaborations with and support activities for other Programs in the Polymers Division including the Polymer Characterization Program, the Polymer Theory and Modeling Program, the Electronic Packaging and Interconnects Program, as well as other agency 
and miscellaneous projects that result from the Program's activities.

In addition, the Program seeks actively to work with Industrial research programs. Activities such as workshops and special symposia that improve the interaction of the Program with outside industry and the general technical and scientific communities are also fostered.

\section{NATIONAL USER FACILITY}

\section{NIST RESEARCH REACTOR}

The NIST Research Reactor (NBSR) and Cold Neutron Research Facility (CNRF) constitute the premier neutron research center in the United States in terms of breadth of capabilities, scope of projects, and number of users. The maintenance and operation of the NBSR and CNRF may be divided into two major activities: 1) to operate the NBSR as a NIST and national resource in a cost-effective manner while assuring the public safety; and 2) to develop and operate the Cold Neutron Research Facility (CNRF) as a national center, providing unique measurement capabilities to U.S. researchers. These responsibilities are allocated, formally, between Reactor Operations and Engineering and the Cold Neutron Project.

Reactor Operations and Engineering activities include the safe and efficient operation of the reactor in order to provide a cost-effective and productive unique national resource. This activity also includes sample irradiations, helping users to design and install new experiments, and monitoring many experimental systems (e.g. the helium refrigerator for cold source cooling). In addition to operation, upgrade and maintenance of the reactor, this activity also includes ensuring compliance with all regulatory requirements.

The Cold Neutron Project activity includes development and operation of the CNRF as a national resource to provide cold neutron measurement capability to a broad research and development community--including materials science, physics, chemistry and biology--which is drawn from industry, universities, and government agencies. This entails the development, operation and maintenance of new cold neutron sources, a network of eight neutron guides, fifteen experimental stations, and a full complement of ancillary equipment such as cryostats, furnaces and magnets. The CNRF, as a national facility, provides measurement capability to outside researchers, on the basis of scientific or technological merit of long-term programs or individual experimental proposals. The Cold Neutron Project activity is responsible for soliciting and evaluating proposals, and administering the allocation of requested experimental facilities and instrument time.

In summary, the maintenance and development of facilities, the development of new applications of neutron measurement technologies, and encouragement of their use by the broadest possible community in the United States, are the primary goals of this program. It is anticipated that new uses of the unique resources provided by the NBSR and CNRF and their associated experimental facilities will lead to continued increases in utilization as has been the case over the last decade. 
TECHNOLOGY TRANSFER 


\section{SUMMARY OF CRADA ACTIVITIES}

Active Agreements

NIST

MSEL

Industry

University

Government

New Agreements

Total Agreements (since 1988)

\section{FY1995}

396

$126(32 \%) *$

109

16

1

18

167

\section{MSEL PARTNERS}

\section{Partners}

Single Agreement

FY1995

Multiple Agreements

TOTAL

82

28

110

Multiple Agreement Partners**

AlliedSignal, Inc. (2)

Aluminum Association, Inc. (2)

American Society for Testing

and Materials (2)

American Superconducting Corp. (2)

Aristech Chemical Corp. (2)

Armstrong World Industries, Inc (2)

BDM, Inc. (2)

Cercom, Inc. (2)

Crucible Metals Corp. (2)

Dentsply International, Inc. (2)

Dow Chemical Co. (4)

E.I. du Pont de Nemours \& Co. (6)

Eaton Corp. (2)

Exxon Research \& Engr. Co. (2)

General Electric Co. (3)

General Electric Corporate R\&D

General Motors Corp. (8)

Goodyear Tire \& Rubber Co. (2)

Grumman Aerospace Corp. (2)

Minnesota Mining \& Manufacturing Co.

(3M) (3)

National Association of Corrosion

Engineers (4)

National Center for Manufacturing

Sciences (2)

Norton Co. (3)

Pennsylvania State University (2)

Raychem Corp. (2)

Rohm and Haas Co. (3)

Sonoscan, Inc (2)

University of Delaware (2)

* MSEL percentage of all active NIST agreements

** Number in parenthesis indicates total number of agreements since 1988 



\begin{tabular}{|c|c|c|c|c|c|c|c|c|c|}
\hline \multirow{5}{*}{ 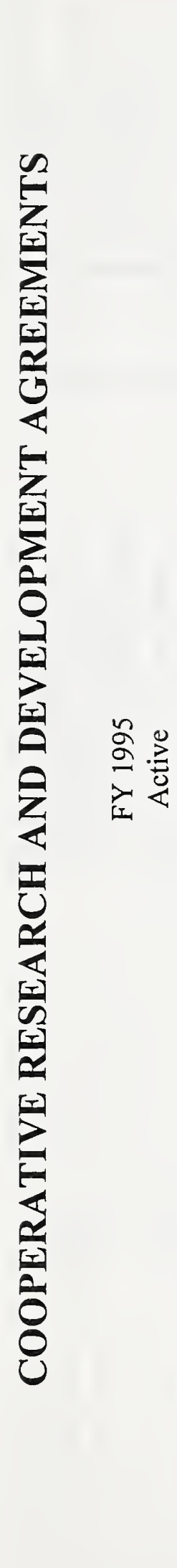 } & \multirow{3}{*}{ 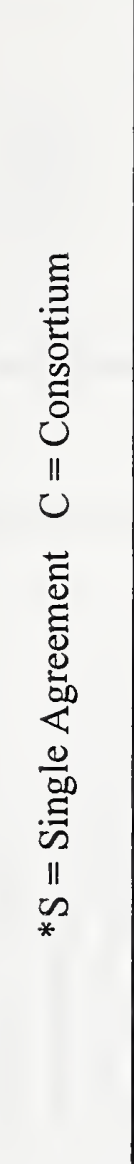 } & 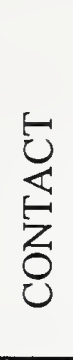 & 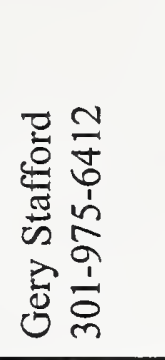 & 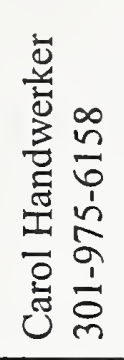 & 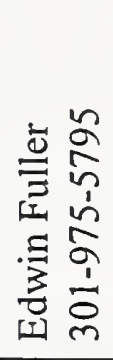 & 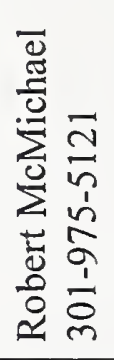 & 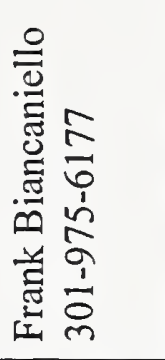 & 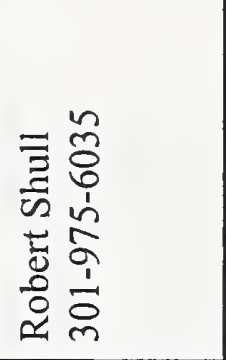 & 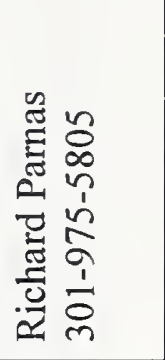 \\
\hline & & 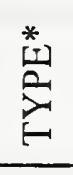 & $n$ & es & 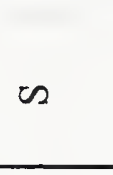 & 0 & $n$ & 0 & $\infty$ \\
\hline & & 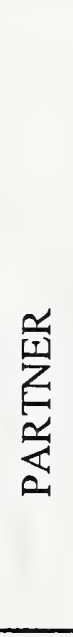 & 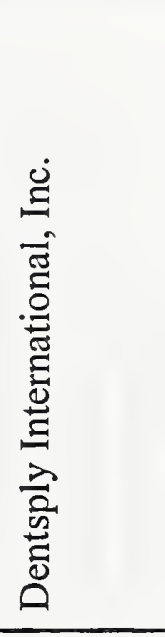 & 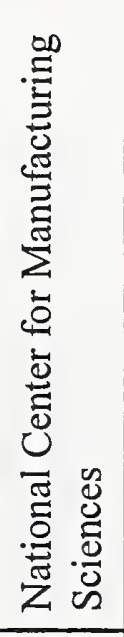 & 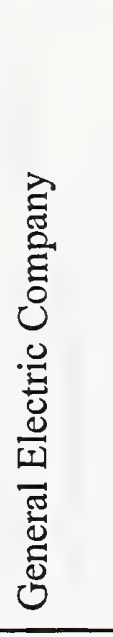 & 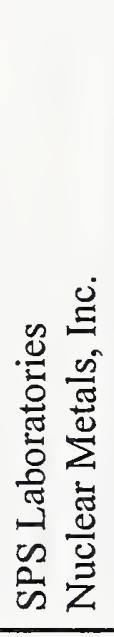 & 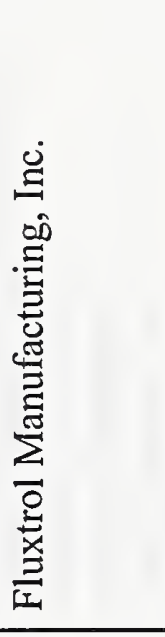 & 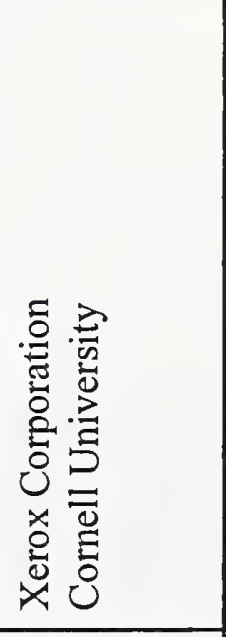 & 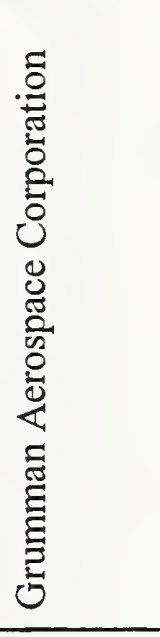 \\
\hline & \multirow[b]{2}{*}{ 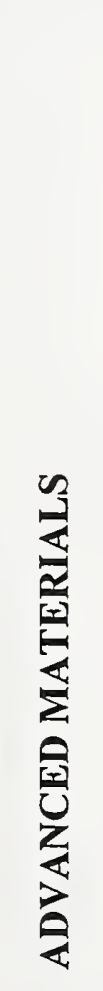 } & 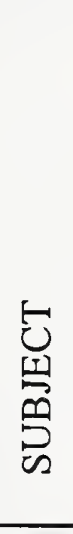 & 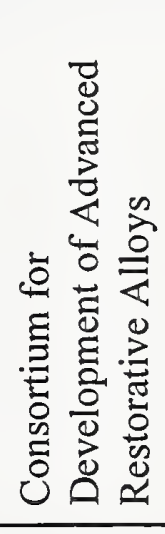 & 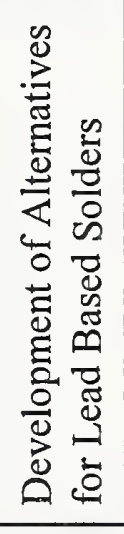 & 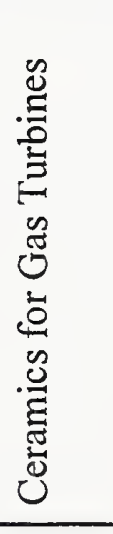 & 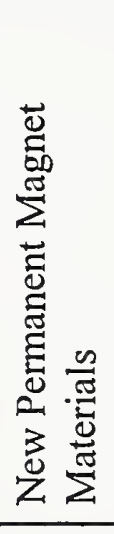 & 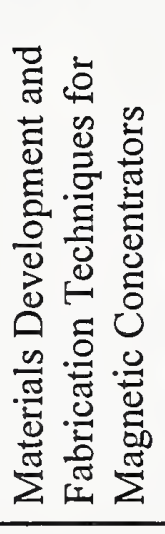 & 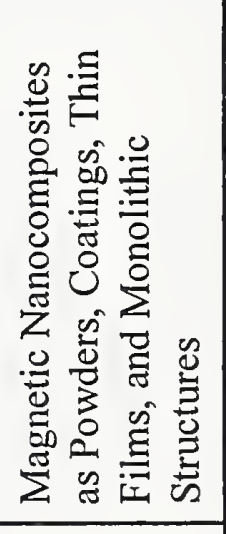 & 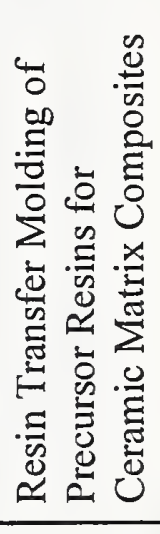 \\
\hline & & 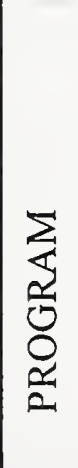 & 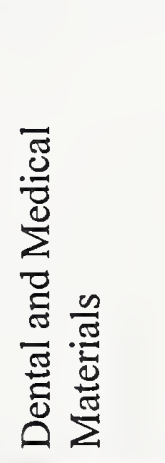 & 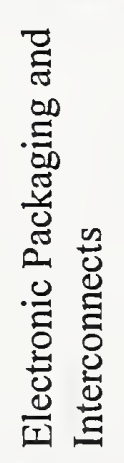 & 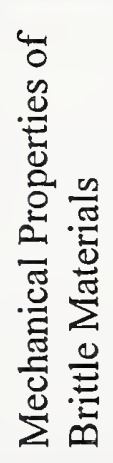 & 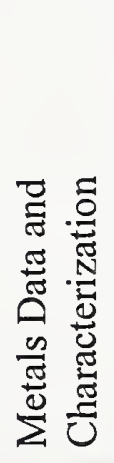 & 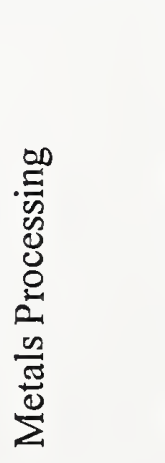 & 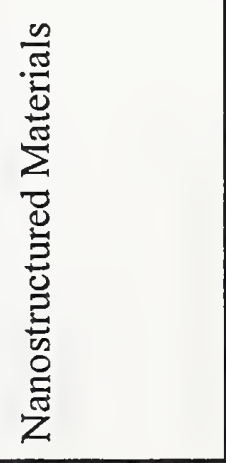 & 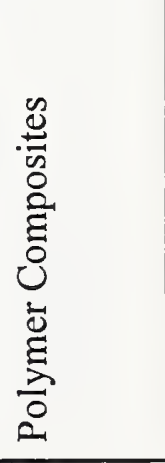 \\
\hline
\end{tabular}




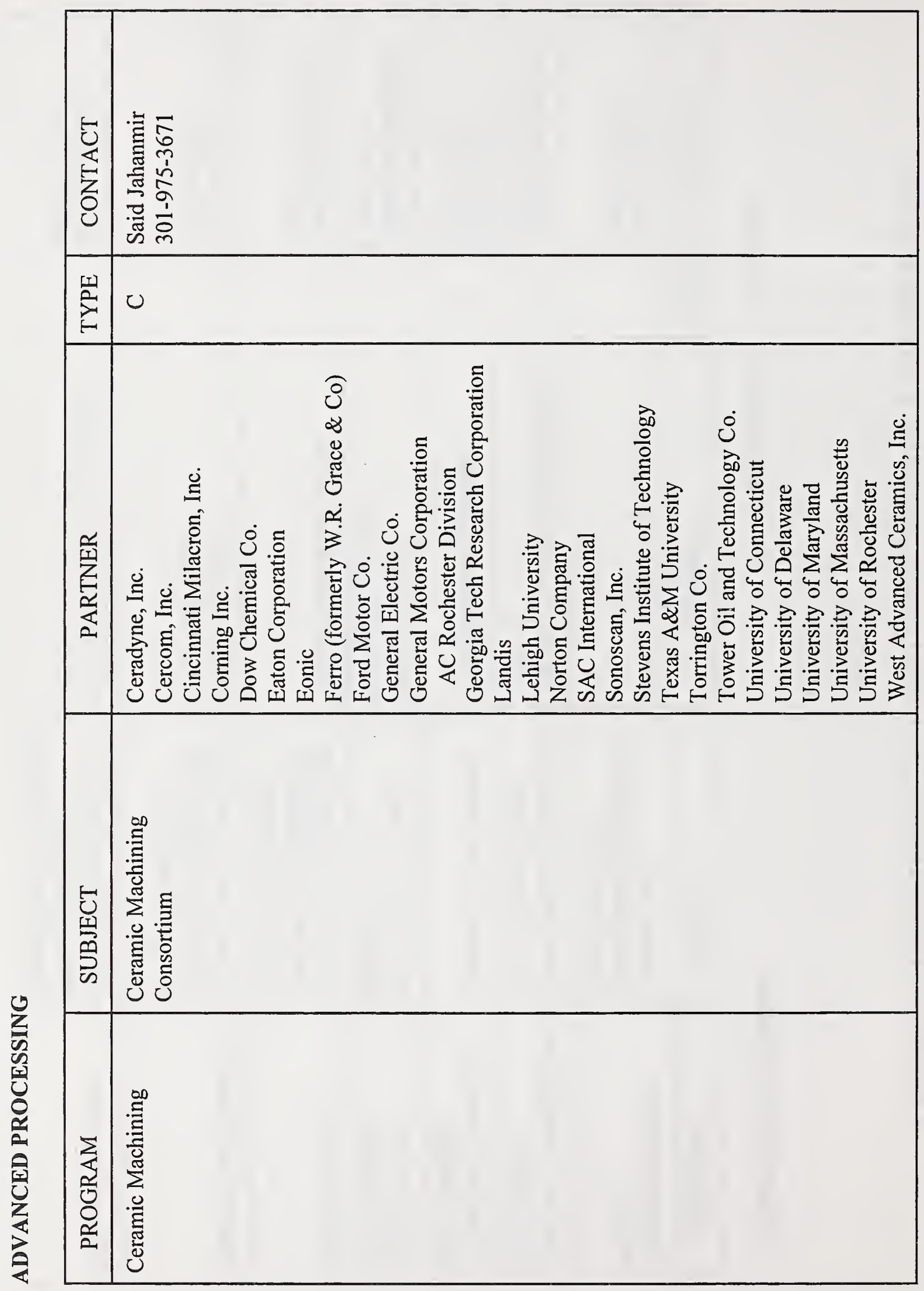




\begin{tabular}{|c|c|c|c|}
\hline & 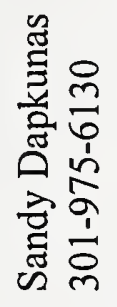 & 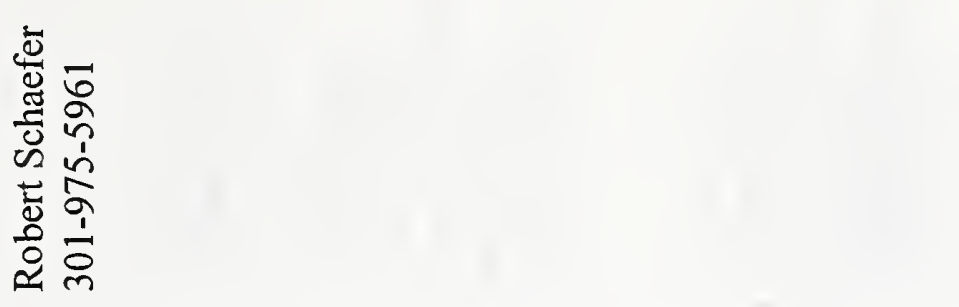 & 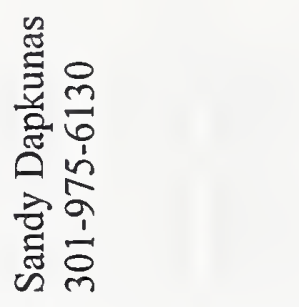 \\
\hline$\stackrel{\frac{1}{2}}{\underline{Z}}$ & $\sim$ & $u$ & 0 \\
\hline & 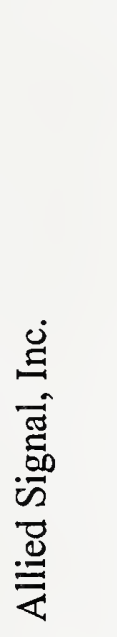 & 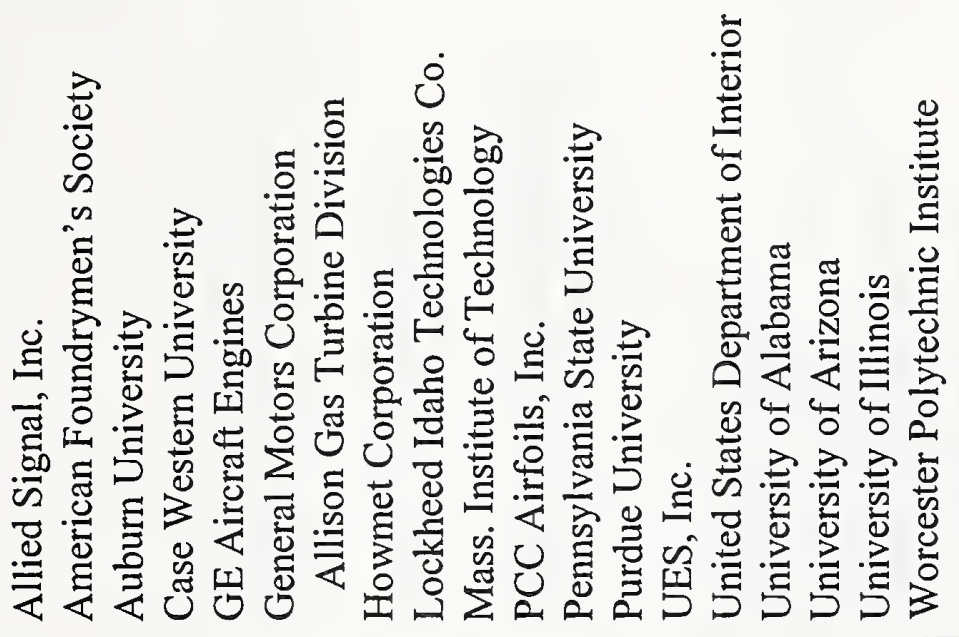 & 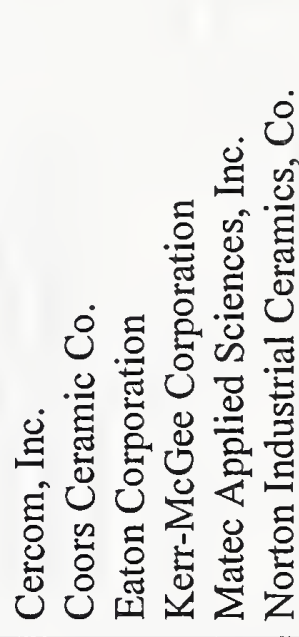 \\
\hline $\begin{array}{l}\hat{y} \\
\text { 品 } \\
\text { 号 }\end{array}$ & 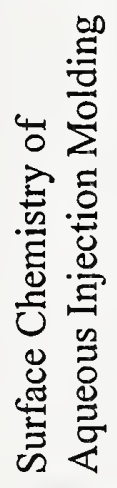 & 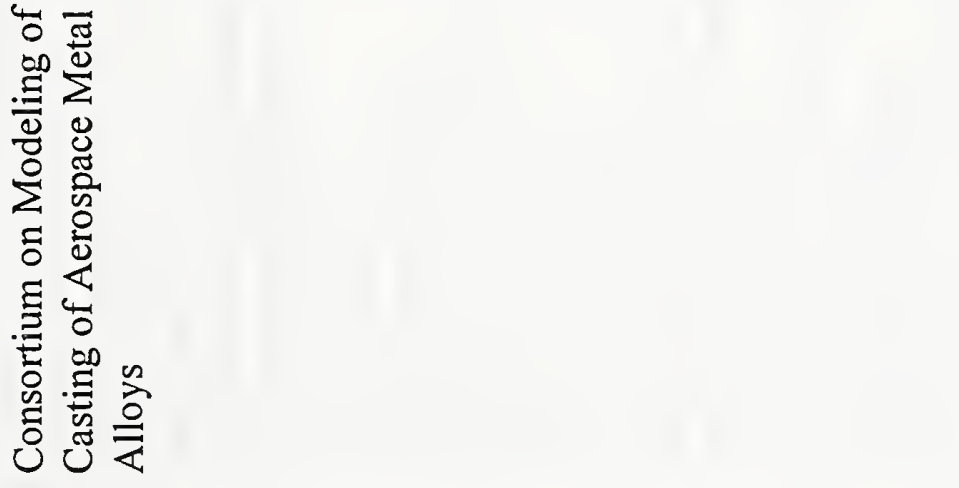 & 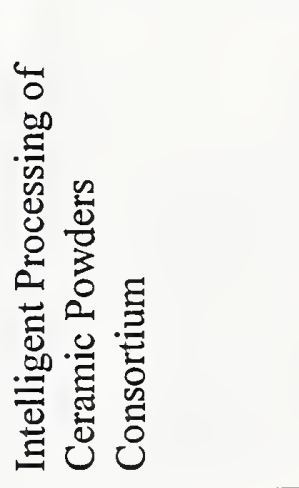 \\
\hline 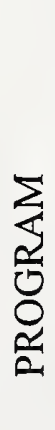 & 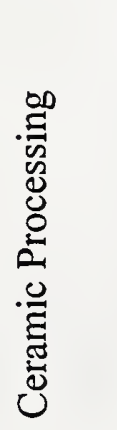 & 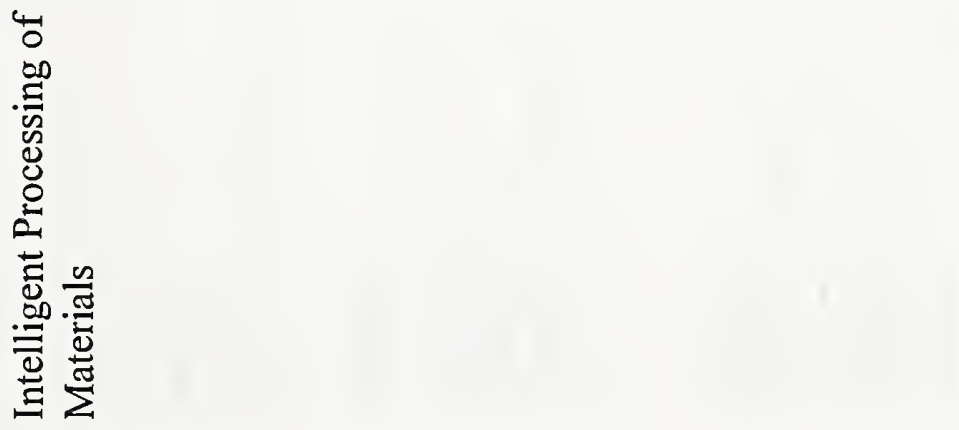 & 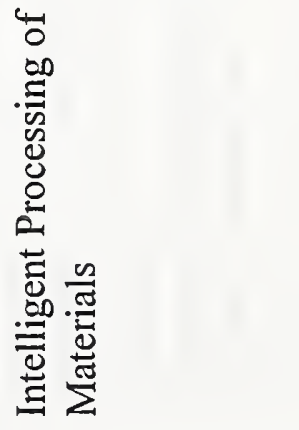 \\
\hline
\end{tabular}




\begin{tabular}{|c|c|c|c|c|c|c|c|c|}
\hline$\underset{\circlearrowright}{\stackrel{U}{U}}$ & 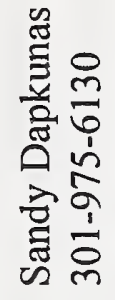 & 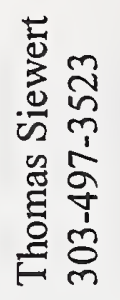 & 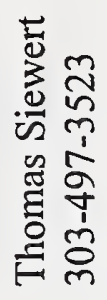 & 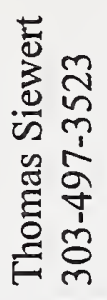 & 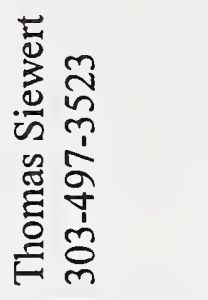 & 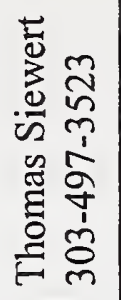 & 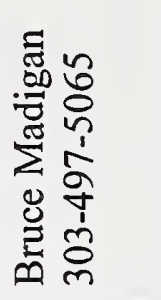 & 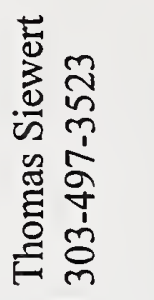 \\
\hline 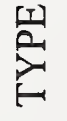 & $\backsim$ & Us & $\sim$ & $\sim$ & $\sim$ & $\sim$ & es & $\sim$ \\
\hline$\frac{\alpha}{z} \underset{\alpha}{\alpha}$ & 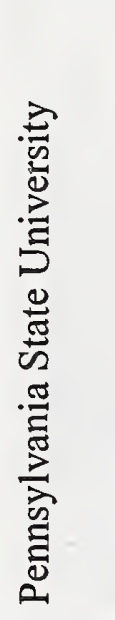 & $\begin{array}{l}\tilde{\Xi} \\
\tilde{\Xi} \\
\tilde{0} \\
0 \\
0 \\
0 \\
0 \\
0 \\
0 \\
0\end{array}$ & 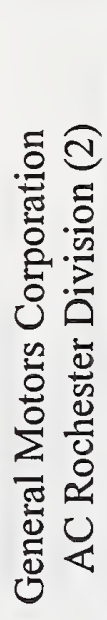 & 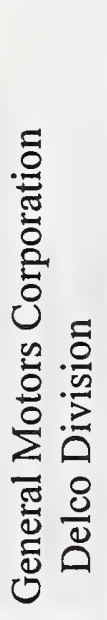 & $\begin{array}{l}0 \\
\Xi \\
\frac{0}{0} \\
0 \\
0 \\
0 \\
0 \\
0 \\
0 \\
0 \\
0 \\
0\end{array}$ & 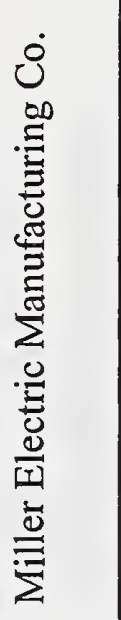 & 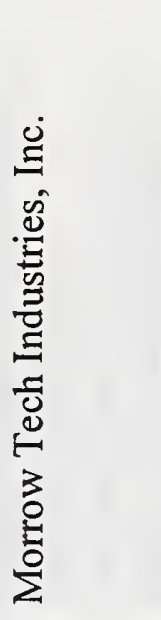 & 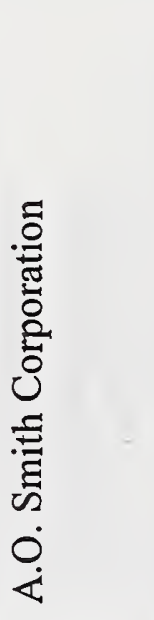 \\
\hline 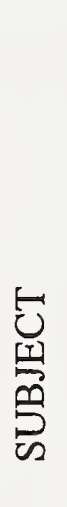 & 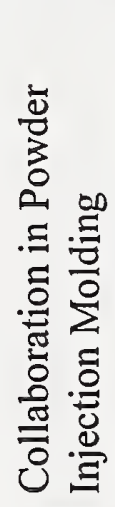 & 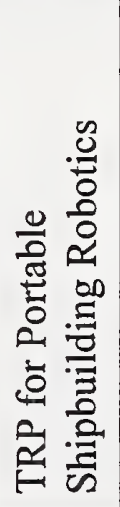 & 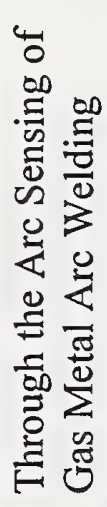 & 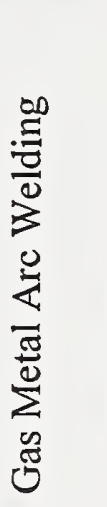 & 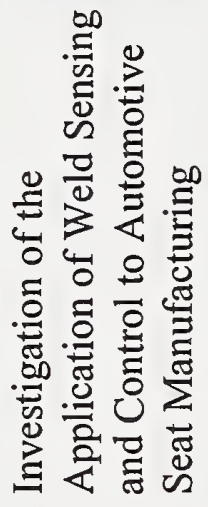 & 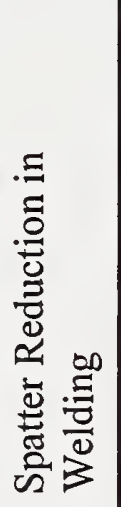 & 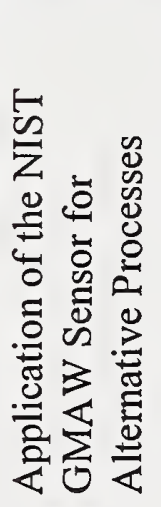 & 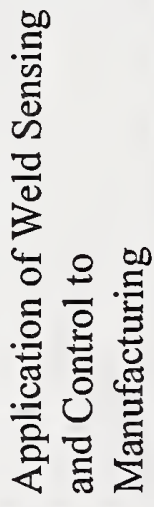 \\
\hline 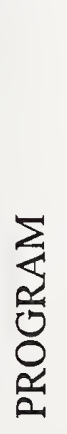 & 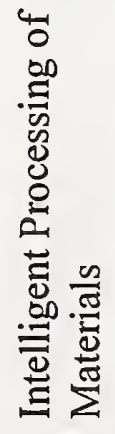 & 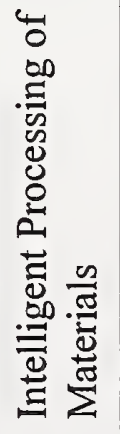 & 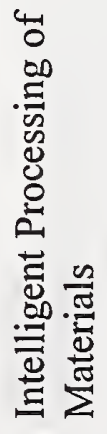 & 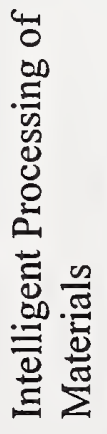 & 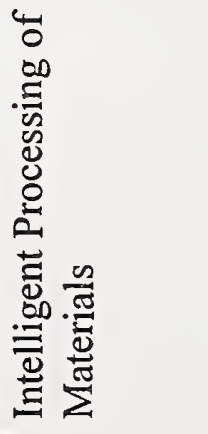 & 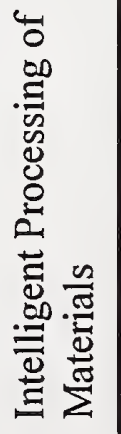 & 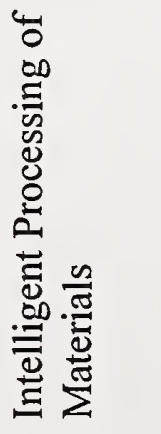 & 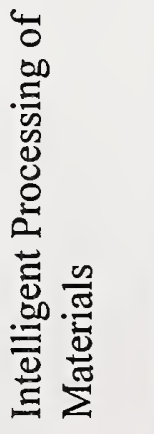 \\
\hline
\end{tabular}




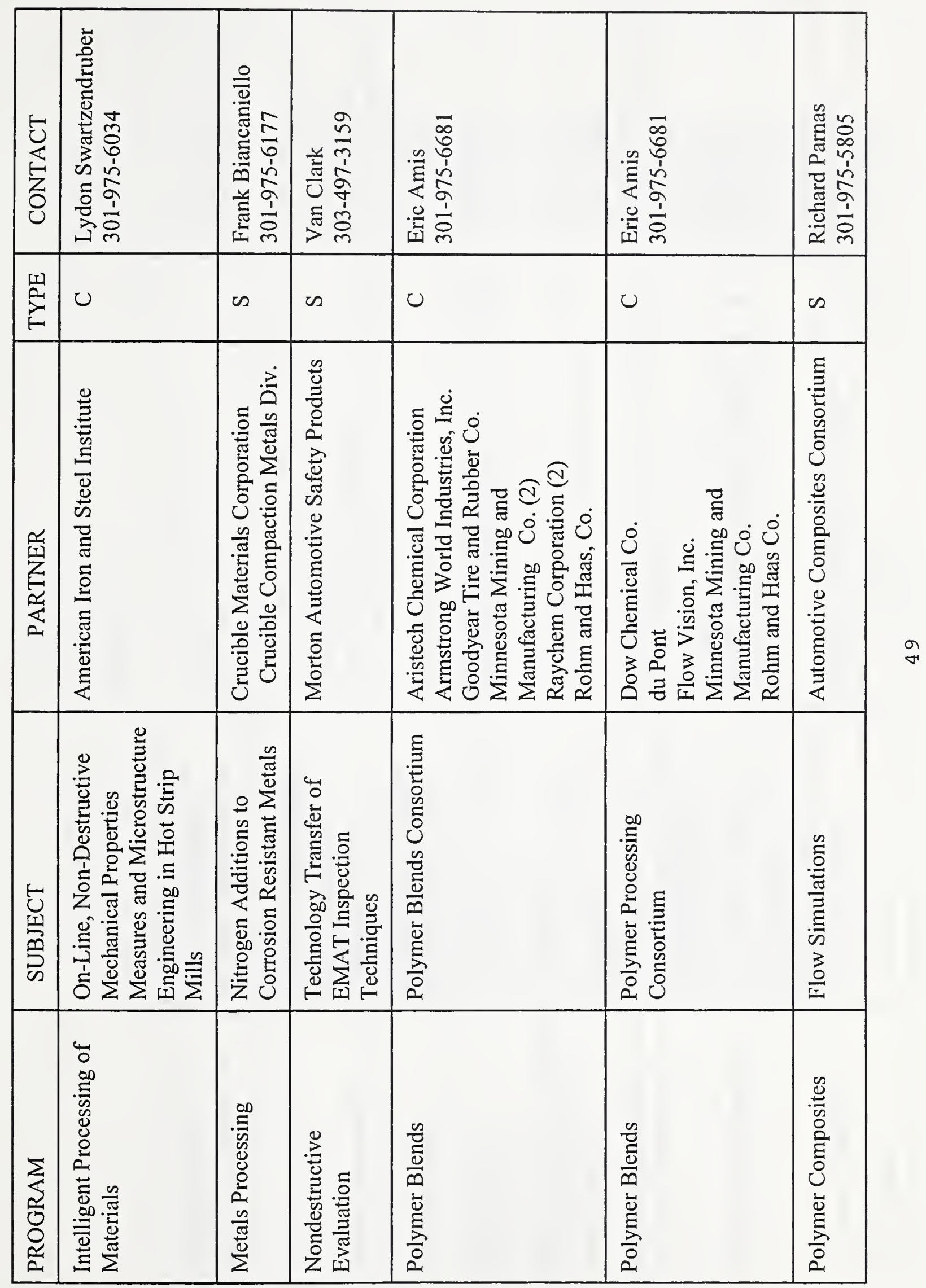




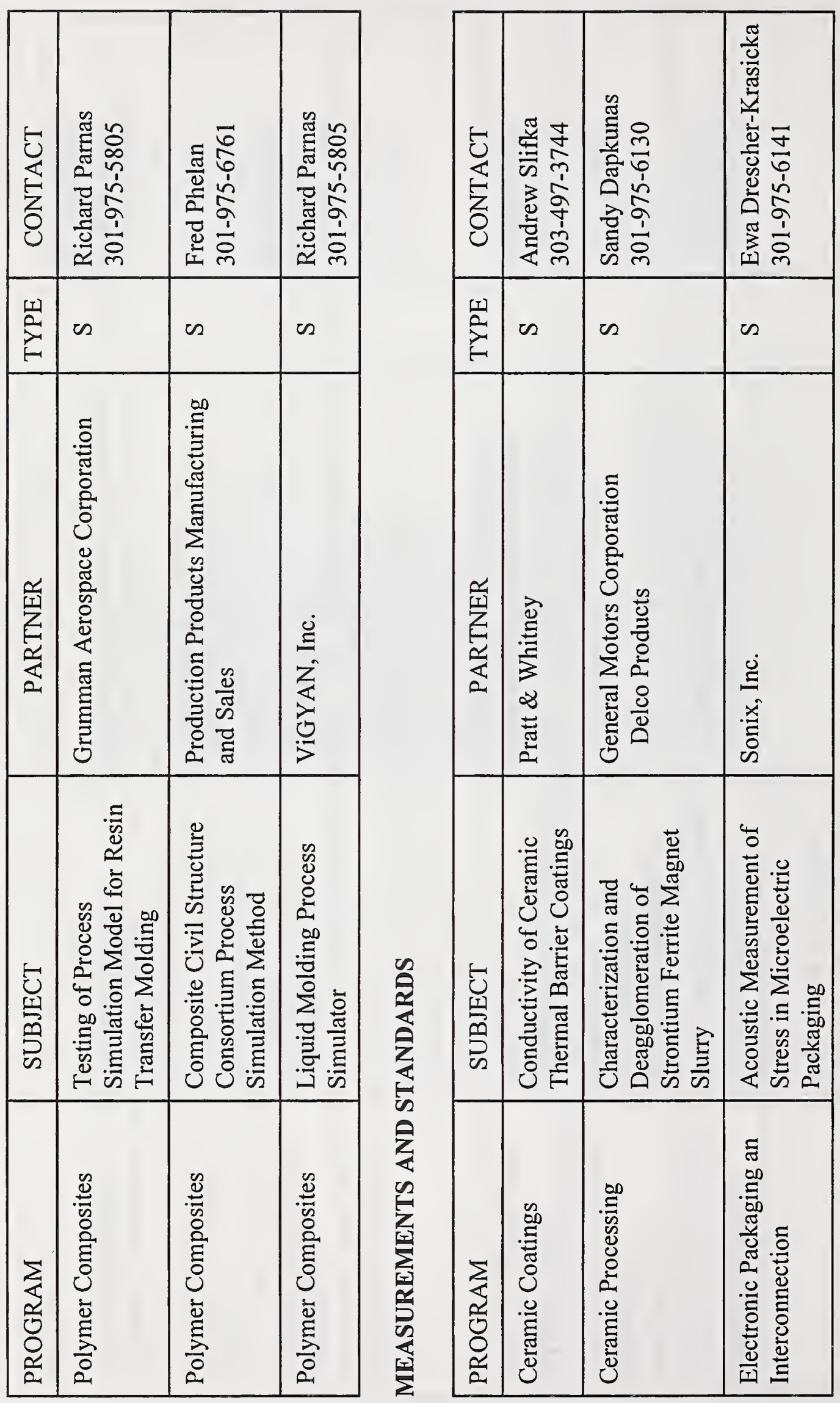

은 


\begin{tabular}{|c|c|c|c|c|c|c|c|c|}
\hline 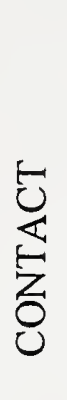 & 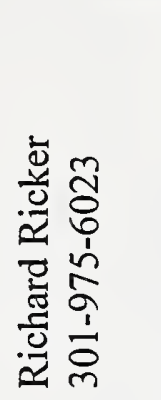 & 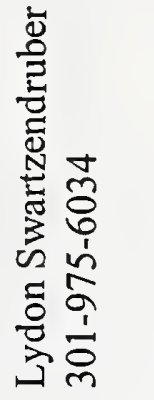 & 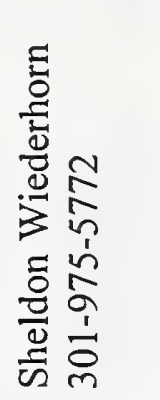 & 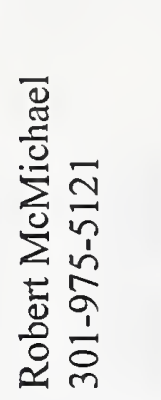 & 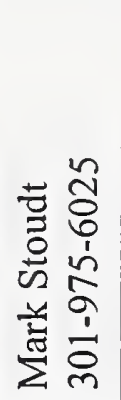 & 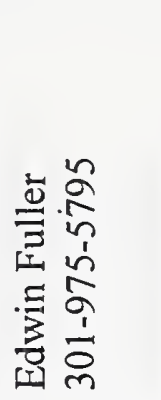 & 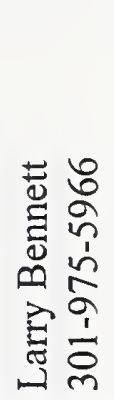 & 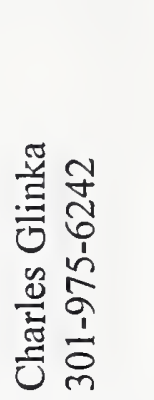 \\
\hline$\sum_{i=}^{\infty}$ & $\sim s$ & $\sim s$ & us & $\sim \Omega$ & Us & $\sim$ & $\sim$ & $\sim$ \\
\hline $\begin{array}{l}\frac{a}{d} \\
\frac{1}{z} \\
\frac{\pi}{\alpha} \\
0\end{array}$ & 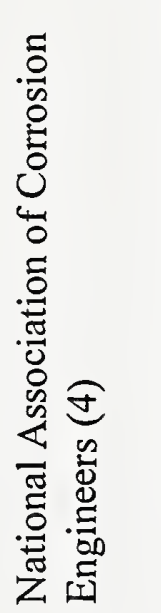 & 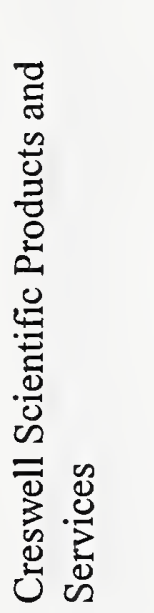 & 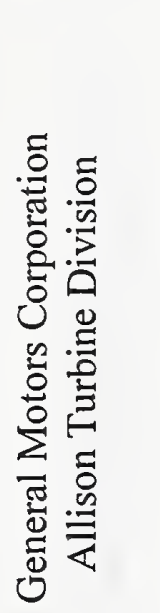 & 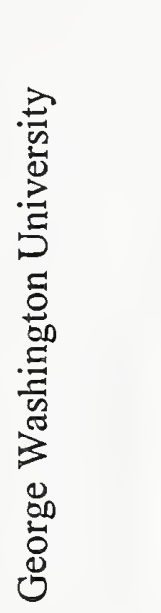 & 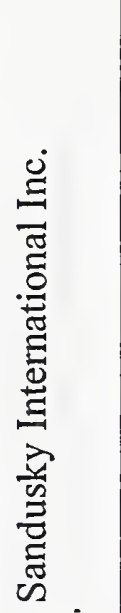 & 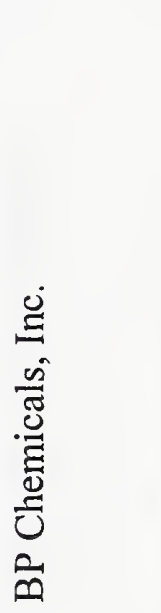 & 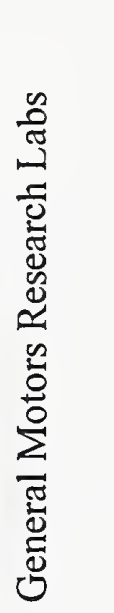 & 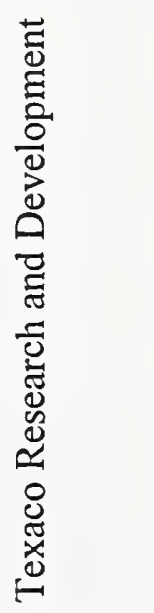 \\
\hline 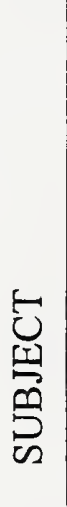 & 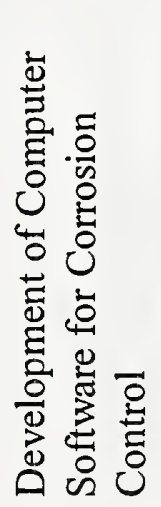 & 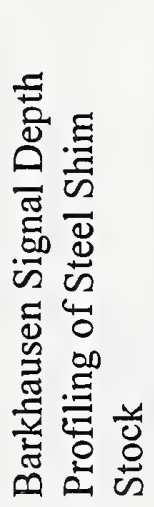 & 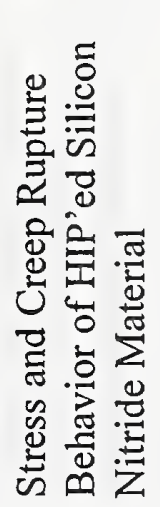 & 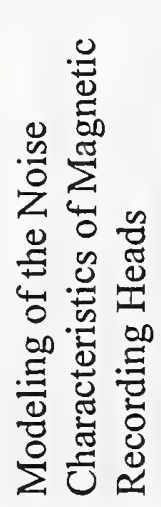 & 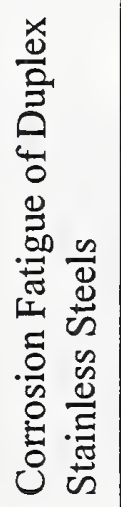 & 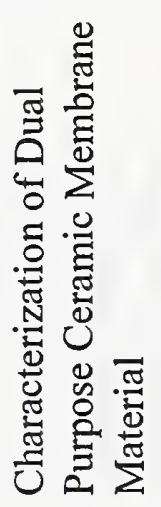 & 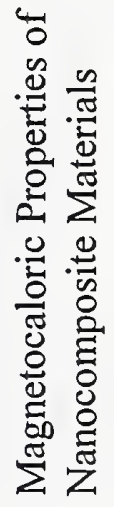 & 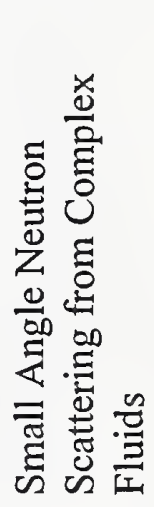 \\
\hline 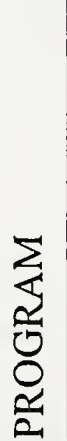 & 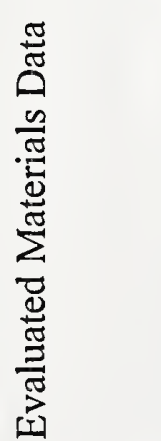 & 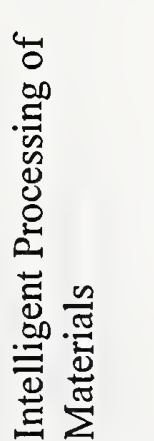 & 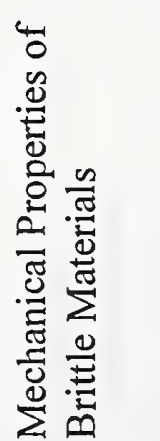 & 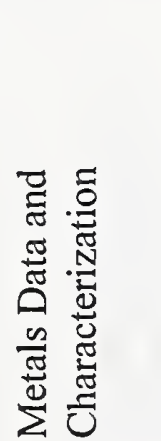 & 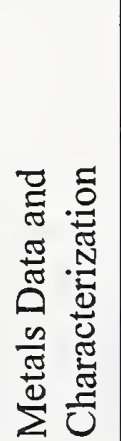 & 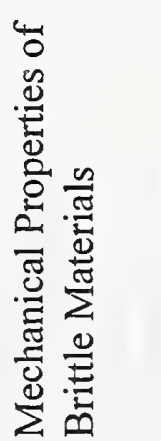 & 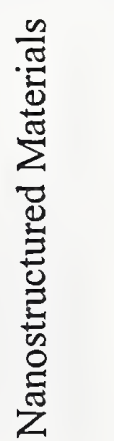 & 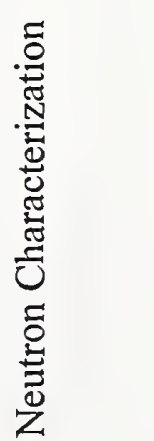 \\
\hline
\end{tabular}




\begin{tabular}{|c|c|c|c|c|c|c|c|}
\hline 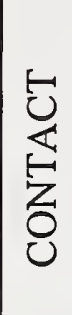 & 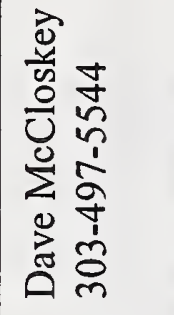 & 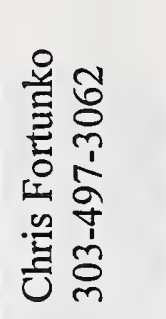 & 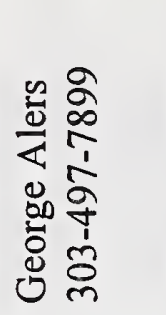 & 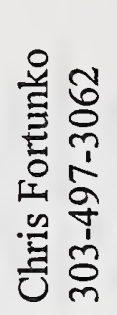 & 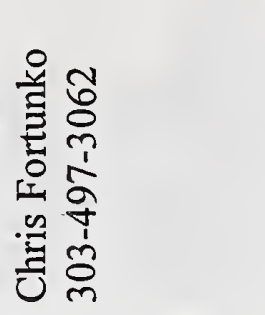 & 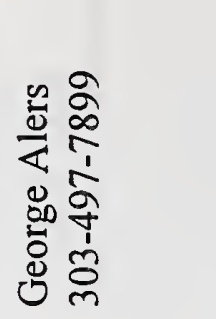 & 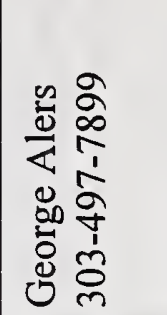 \\
\hline 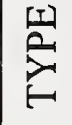 & $\sim s$ & $\sim s$ & $\theta s$ & 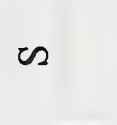 & $\sim s$ & us & $\approx s$ \\
\hline 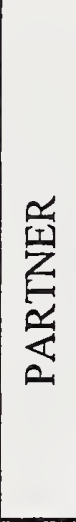 & $\begin{array}{l}\vec{v} \\
\text { 吉 }\end{array}$ & 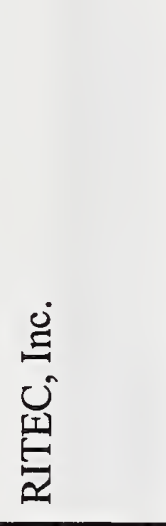 & 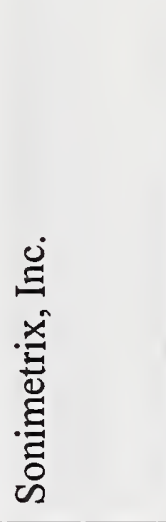 & 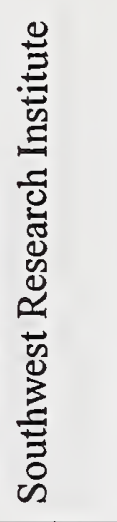 & 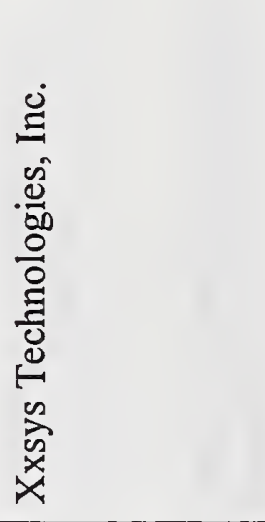 & 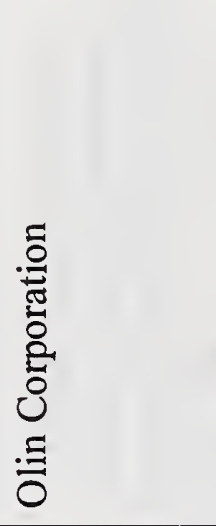 & 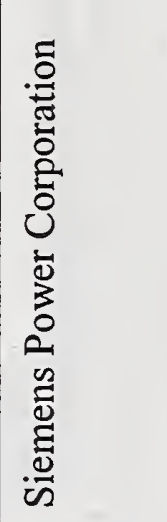 \\
\hline $\begin{array}{l}\text { 屶 } \\
\text { 品 } \\
\text { 号 }\end{array}$ & 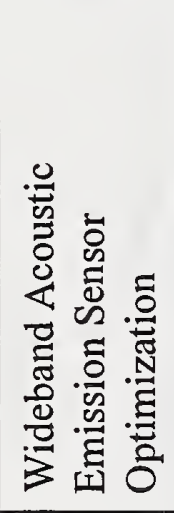 & 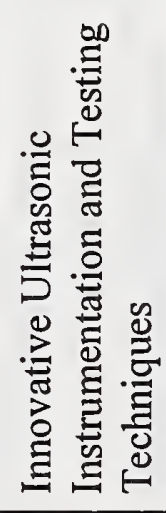 & 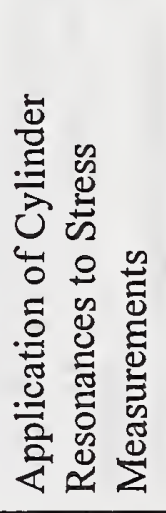 & 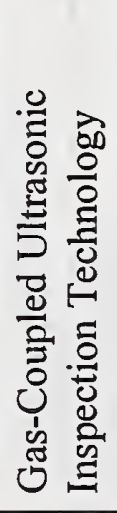 & 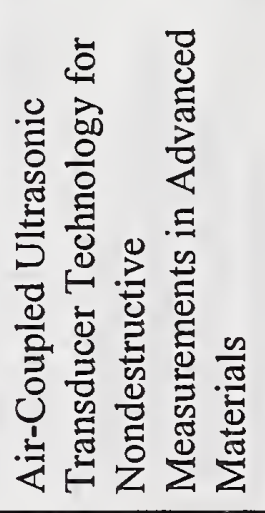 & 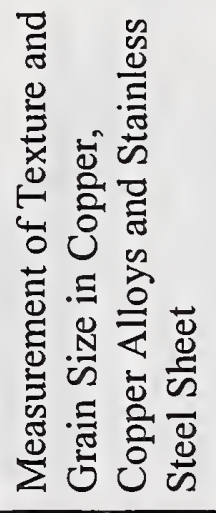 & 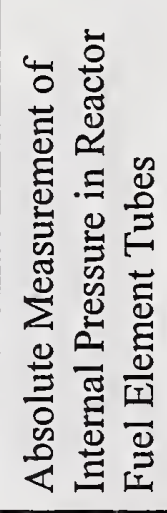 \\
\hline $\begin{array}{l}\sum \\
\text { 离 } \\
0 \\
\text { 足 }\end{array}$ & 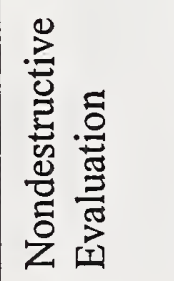 & 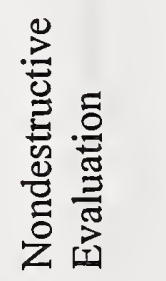 & 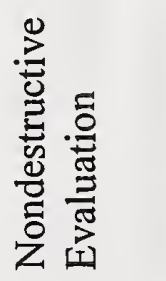 & 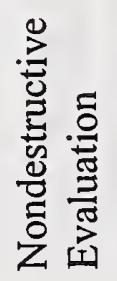 & 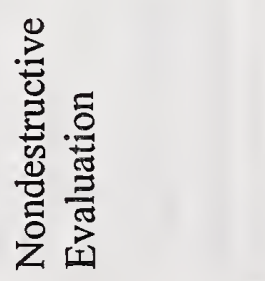 & 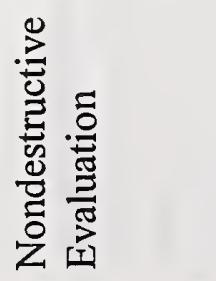 & 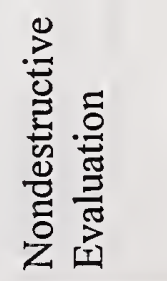 \\
\hline
\end{tabular}

ก 


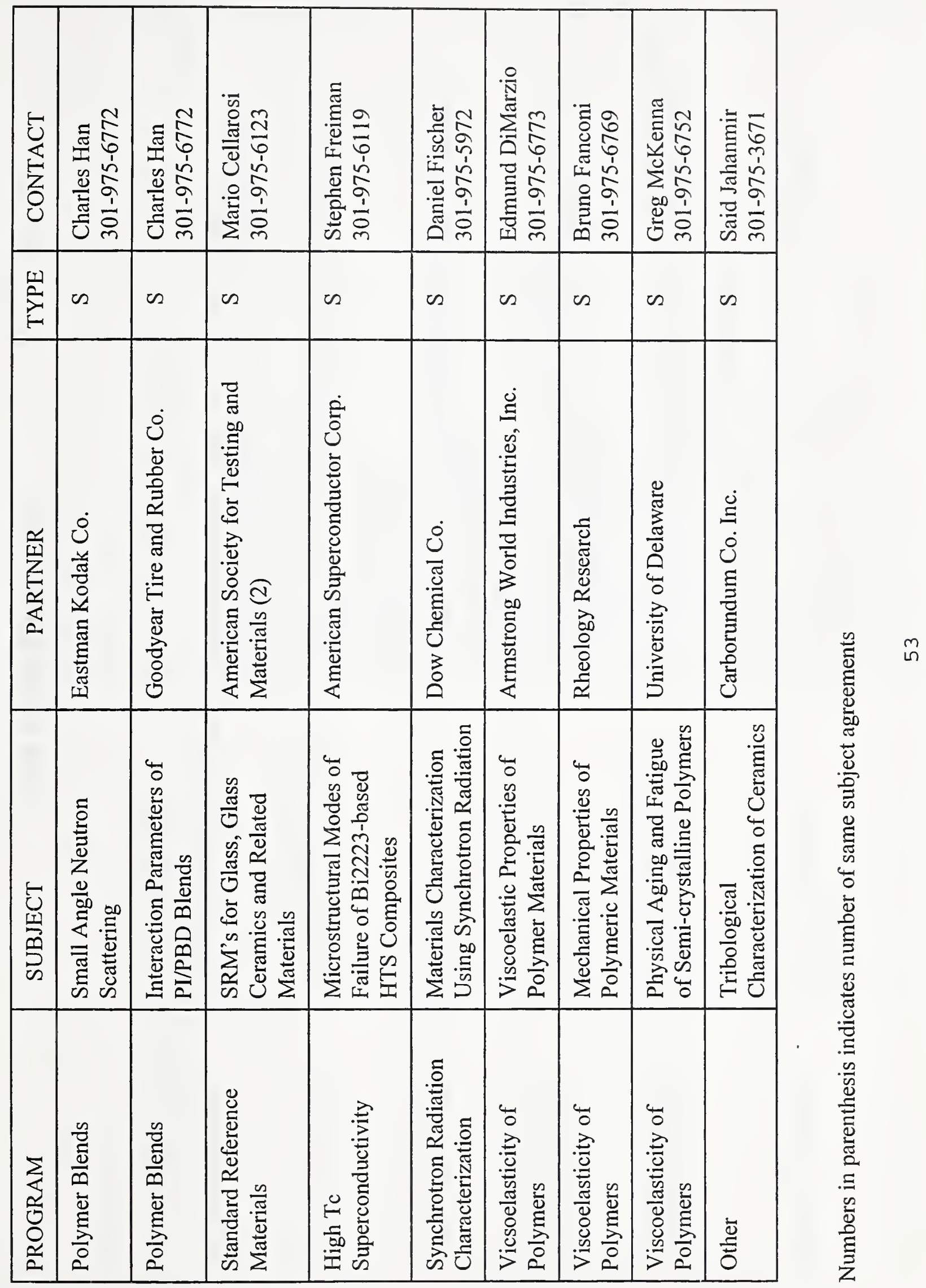





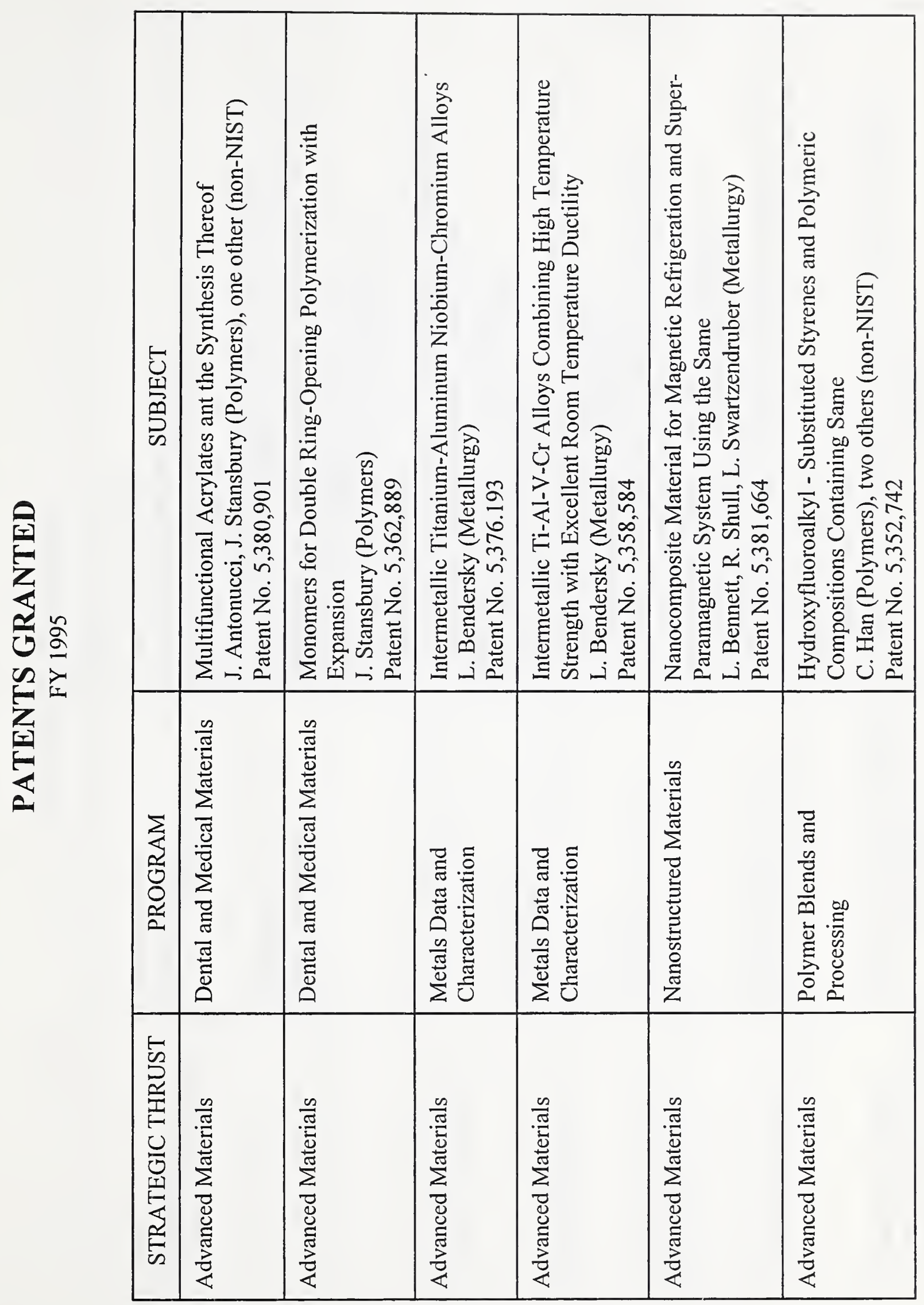

ก 


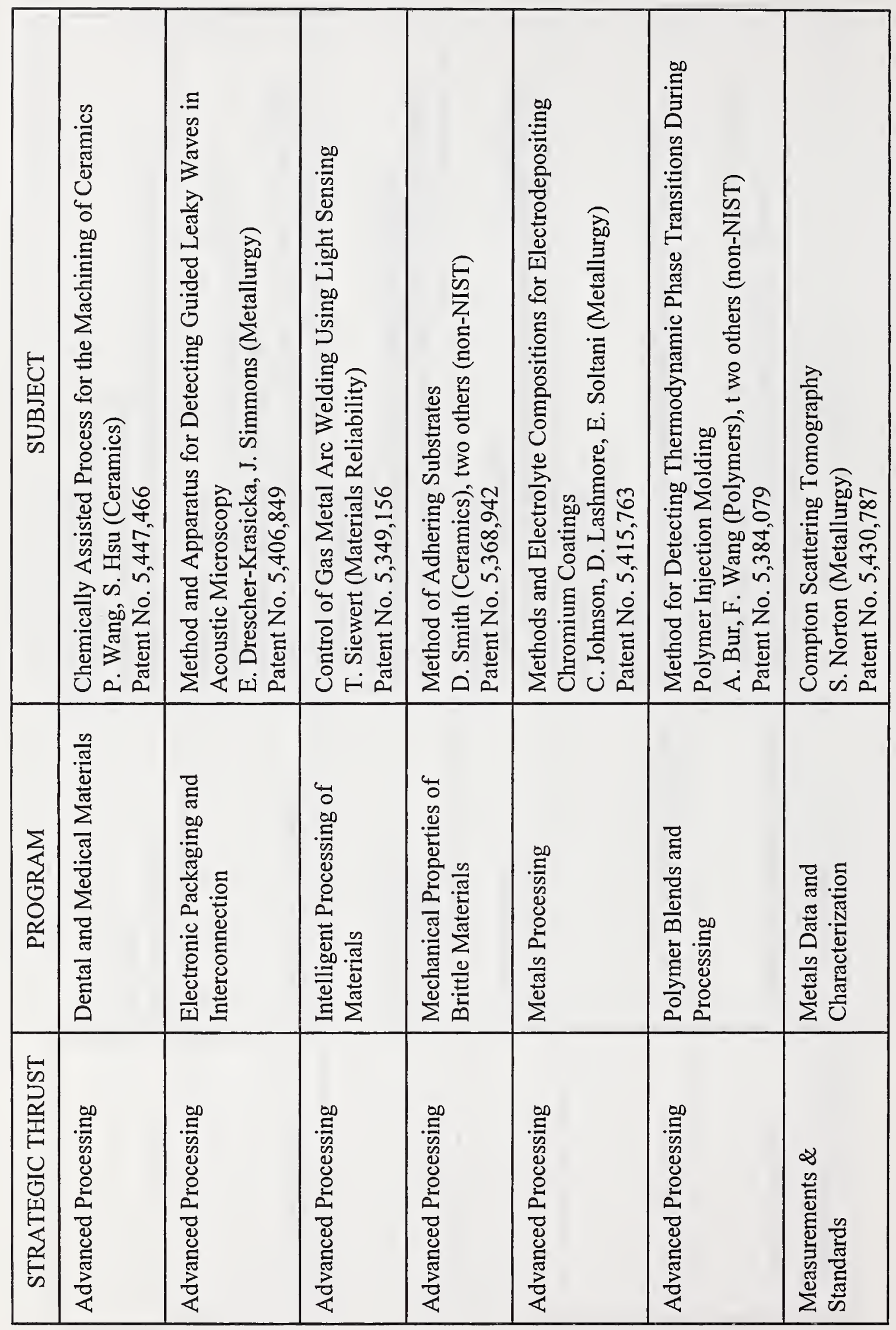




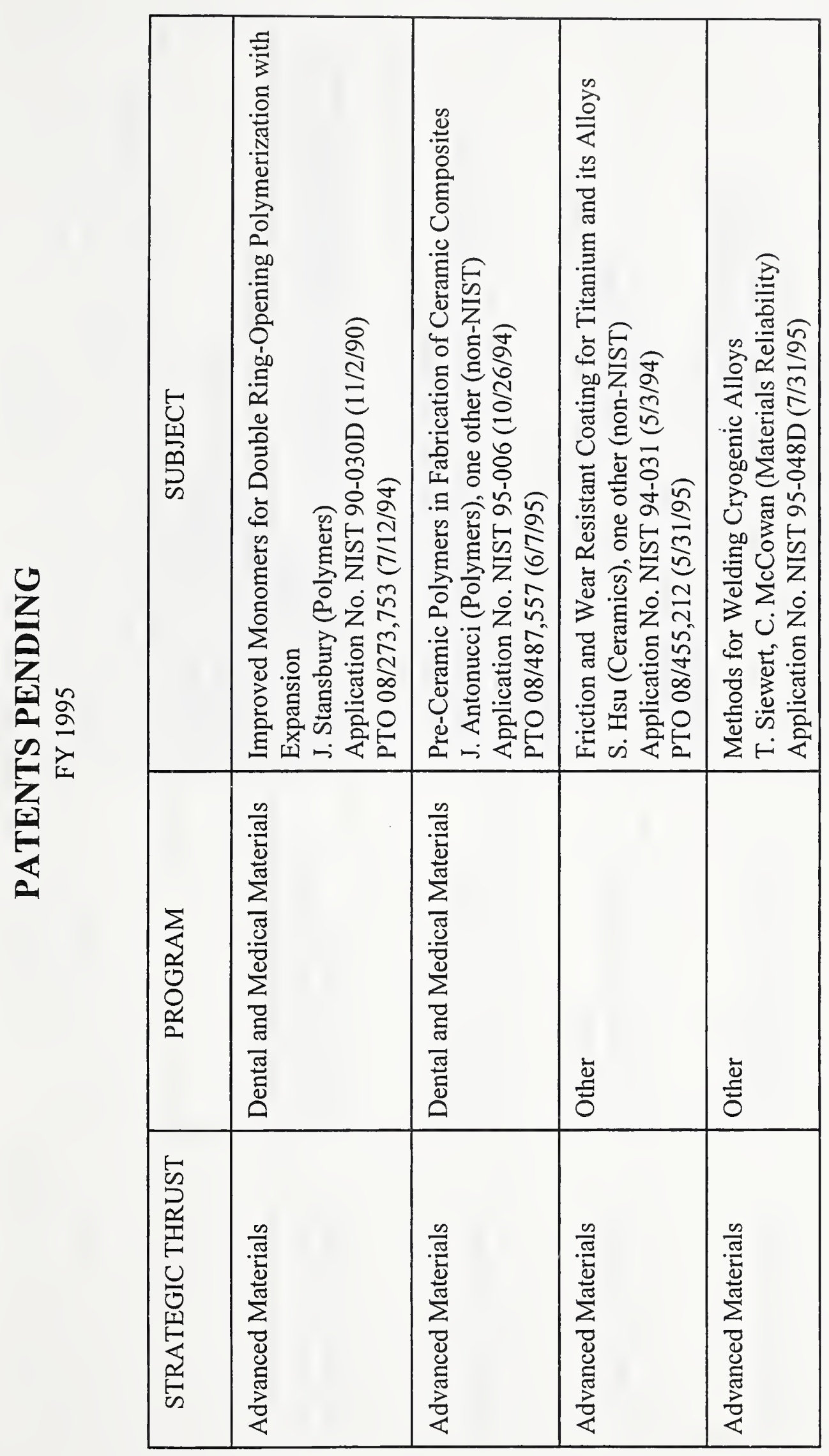




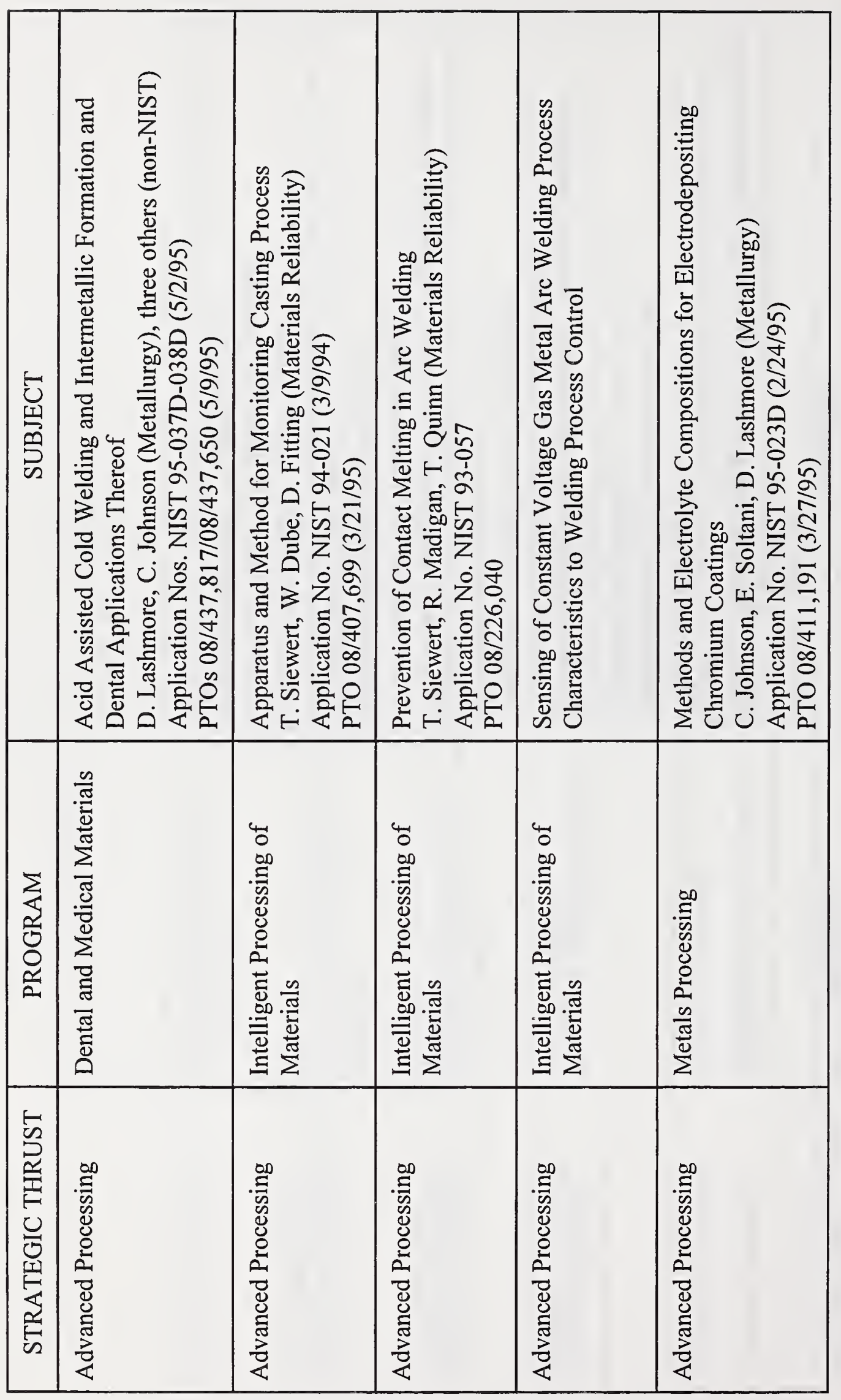

$\infty$
in 


\begin{tabular}{|c|c|c|}
\hline 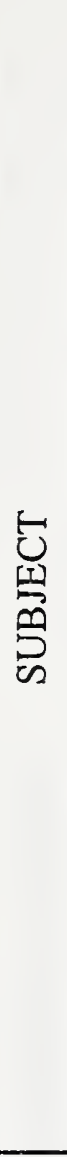 & 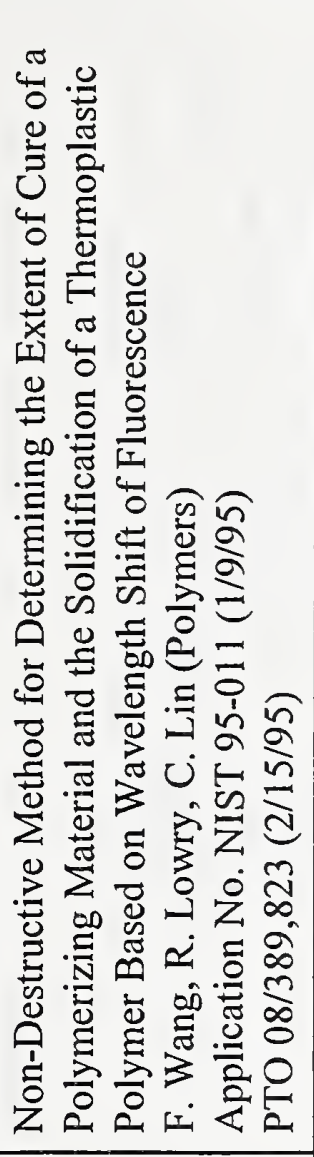 & 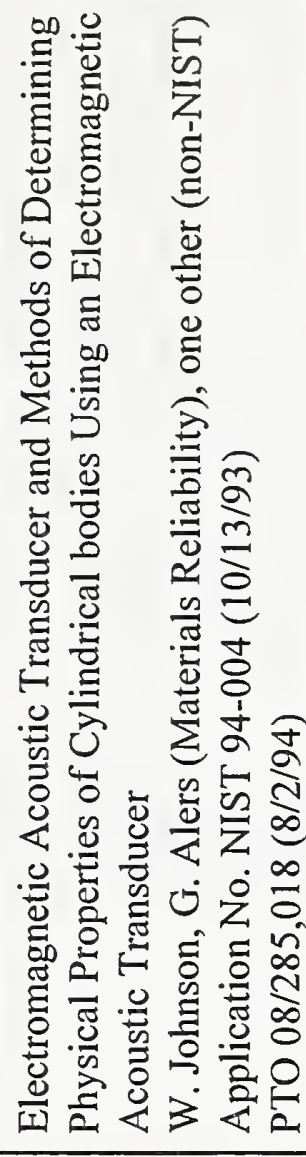 \\
\hline & 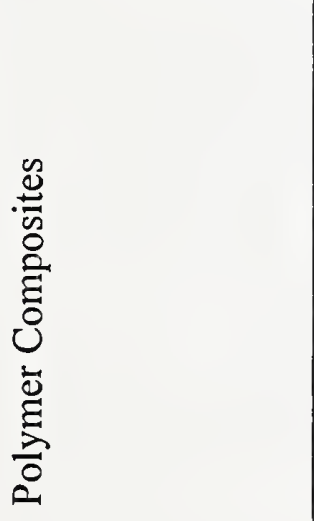 & 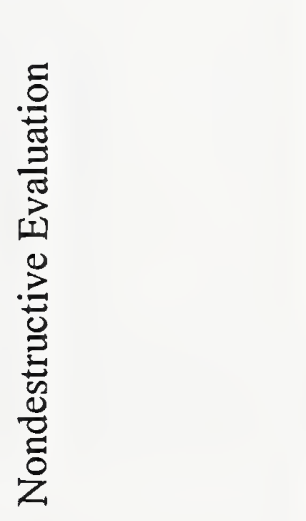 \\
\hline 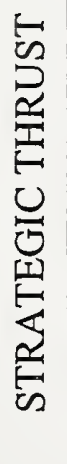 & 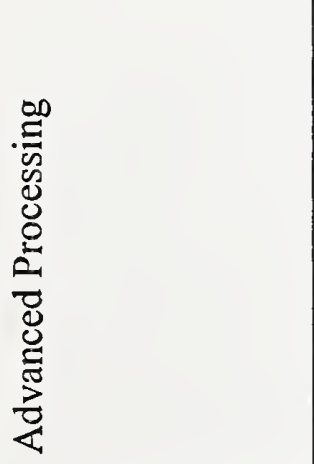 & 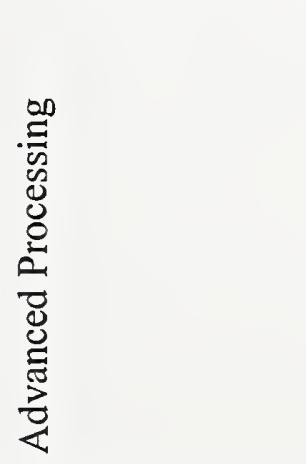 \\
\hline
\end{tabular}





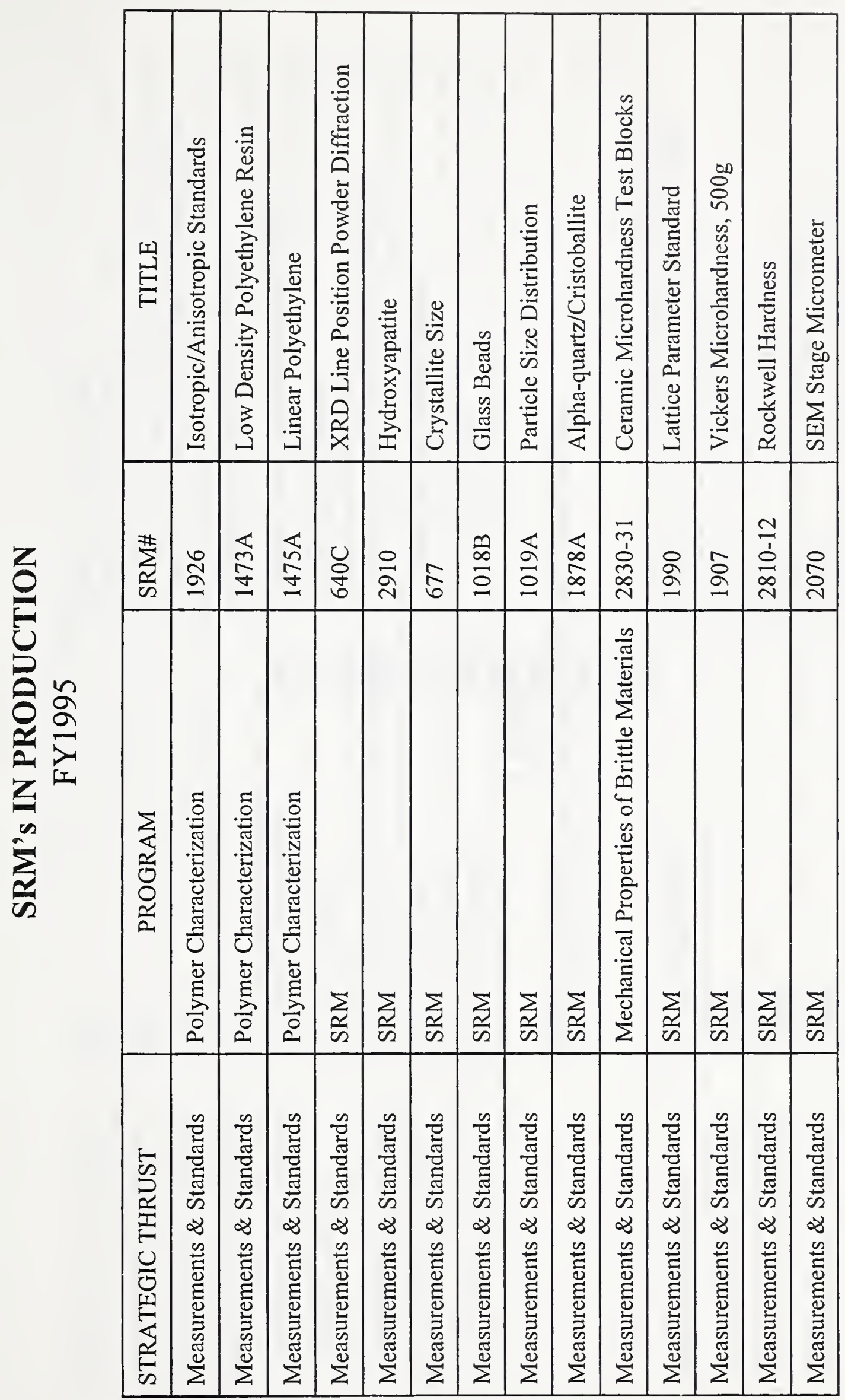




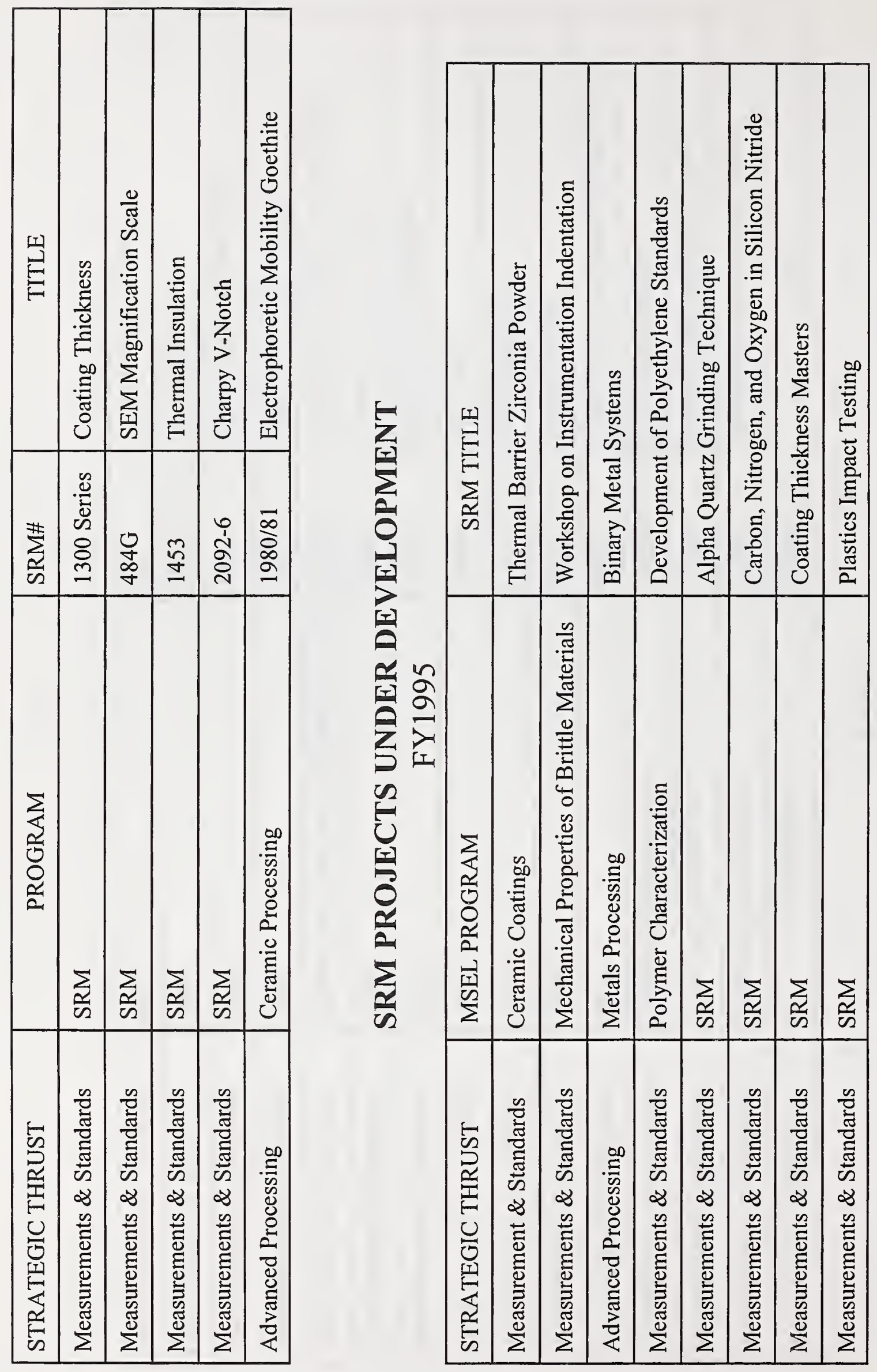


APPENDICES 



\section{HONORS AND AWARDS}

FY1995

\section{DEPARTMENT OF COMMERCE AWARDS}

\section{GOLD MEDAL (Exceptional Service)}

Donald L. Hunston

for providing permeability test methods and standar to advance the high-speed, low-cost fabrication of structural composites using liquid molding processes.

\section{SILVER MEDAL (Meritorious Service)}

John H. Nicklas

(Deceased)

James A. Beatty

Dennis E. Brady

Keith D. Hall

Paul J. Liposky

George D. Reilly

Lynn A. Shuman

Mahesh A. Suthar for a major system upgrade of the NIST Research Reactor - the most cost-effective neutron research facility in the world.

\section{BRONZE MEDAL (Superior Service)}

Michael A. Schen

George M. Baltic

Michael J. Rinehart for outstanding contributions to the creation of the NIST program in microelectronic packaging and interconnections.

For skill, dedication, and professionalism in the installation of the neutron guide network at the NIST Research Reactor. 


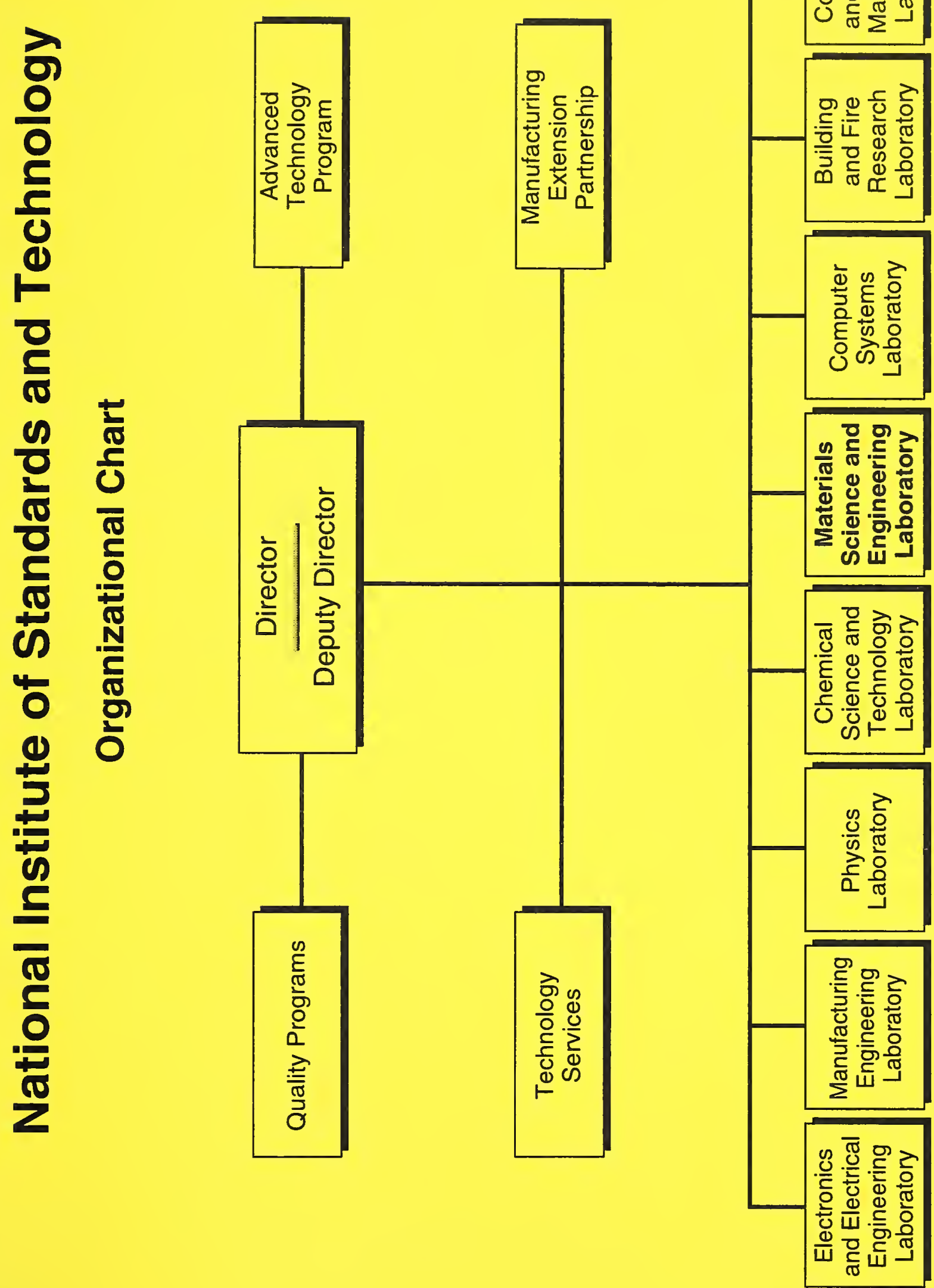
